OPEN ACCESS

Edited by:

Ralf Georg Dietzgen,

The University of Queensland

Australia

Reviewed by:

Manfred Heinlein,

Centre National de la Recherche

Scientifique (CNRS), France

Benjamin George Kopek,

Hope College, United States

${ }^{*}$ Correspondence:

Jean-François Laliberté jean-francois.laliberte@iaf.inrs.ca Yongliang Zhang

cauzhangy!@cau.edu.cn

Specialty section:

This article was submitted to

Virology,

a section of the journa

Frontiers in Plant Science

Received: 03 October 2017 Accepted: 11 January 2018

Published: 30 January 2018

Citation:

Jin $X$, Cao X, Wang $X$, Jiang J, Wan J, Laliberté J-F and Zhang Y (2018)

Three-Dimensional Architecture and Biogenesis of Membrane Structures Associated with Plant Virus

Replication. Front. Plant Sci. 9:57. doi: 10.3389/fpls.2018.00057

\section{Three-Dimensional Architecture and Biogenesis of Membrane Structures Associated with Plant Virus Replication}

\author{
Xuejiao Jin ${ }^{1}$, Xiuling Cao ${ }^{1}$, Xueting Wang ${ }^{1}$, Jun Jiang ${ }^{2}$, Juan Wan ${ }^{2}$, \\ Jean-François Laliberté ${ }^{2 *}$ and Yongliang Zhang ${ }^{1 *}$
}

${ }^{1}$ State Key Laboratory of Agro-Biotechnology and Ministry of Agriculture Key Laboratory of Soil Microbiology, College of Biological Sciences, China Agricultural University, Beijing, China, ${ }^{2}$ Institut National de la Recherche

Scientifique-Institut Armand-Frappier, Laval, QC, Canada

Positive-sense (+) RNA viruses represent the most abundant group of viruses and are dependent on the host cell machinery to replicate. One remarkable feature that occurs after (+) RNA virus entry into cells is the remodeling of host endomembranes, leading to the formation of viral replication factories. Recently, rapid progress in threedimensional (3D) imaging technologies, such as electron tomography (ET) and focused ion beam-scanning electron microscopy (FIB-SEM), has enabled researchers to visualize the novel membrane structures induced by viruses at high resolution. These 3D imaging technologies provide new mechanistic insights into the viral infection cycle. In this review, we summarize the latest reports on the cellular remodeling that occurs during plant virus infection; in particular, we focus on studies that provide 3D architectural information on viral replication factories. We also outline the mechanisms underlying the formation of these membranous structures and discuss possible future research directions.

Keywords: plant virus, viral replication factories, cellular remodeling, three-dimensional architecture, biogenesis

\section{INTRODUCTION}

Positive-strand (+) RNA viruses induce extensive endomembrane reorganizations in the host cell to create a favorable microenvironment for their replication (Verchot, 2011; Romero-Brey and Bartenschlager, 2014). These remodeled membranous structures are thought to sequester virus replication processes away from host defense systems, such as RNA silencing. They are also thought to compartmentalize viral RNA, viral proteins, and the diverse host factors for high-efficiency synthesis of progeny RNAs (Schwartz et al., 2004; Novoa et al., 2005; Miller and Krijnse-Locker, 2008; Verchot, 2011).

Conventional transmission electron microscopy (TEM) provides only random or discontinuous pictures of cellular organelles (Baumeister, 2002) and thus may lead to misconceptions regarding cellular ultrastructure. For example, three-dimensional (3D) analysis of turnip mosaic virus (TuMV)-induced intracellular rearrangements revealed that the vesicle-like structures in twodimensional (2D) TEM images are, in fact, tubules (Wan et al., 2015). To overcome the limitations of the random sectioning used in traditional TEM analysis, many novel 3D electron microscopy methods have been developed, including serial sectioning, electron tomography (ET), scanning 
transmission electron microscopy (STEM) tomography, serial block-face SEM (SBF-SEM), FIB-SEM, cryo-ET, and cryo-FIBSEM (Romero-Brey and Bartenschlager, 2015). The development of these approaches has improved our understanding of the membrane rearrangements that occur during plant virus infection (Laliberté and Zheng, 2014; Risco et al., 2014; Harak and Lohmann, 2015; Fernández de Castro et al., 2017). This review provides a comprehensive overview of recent major progress in the $3 \mathrm{D}$ analysis of plant (+) RNA virus replication compartments and the mechanisms underlying their formation.

\section{D IMAGING TECHNIQUES FOR THE RECONSTRUCTION OF VIRAL REPLICATION FACTORIES}

Limited information is obtained from conventional TEM due to the small thickness of thin sections. Hence, serial sectioning is emerging as a method to overcome this problem. A long ribbon of serial sections is needed, and hundreds to thousands of micrographs are recorded from the serial sections. The micrographs are aligned and processed to a stack. 3D structures can be generated from the stack of images. Although it provides more information than conventional TEM, serial sectioning has several drawbacks. For example, this sectioning requires welltrained staff to obtain high-quality serial sections without losing a single section, and the discontinuities between two consecutive sections often create difficulties in the alignment of images.

In contrast to serial sectioning, more ultrastructural information can be obtained from thicker sections by electron tomography (ET). ET is a powerful technique that yields highly informative images of subcellular architecture in three dimensions using thick sections; it can show a wide range of subcellular structures present in 200-400-nm-thick resin sections at 3-8-nm resolution (Mastronarde, 1997; McIntosh et al., 2005). The images are collected using 200-400 kV intermediate voltage electron microscope (IVEM) with a eucentric specimen rod and a charge-coupled-device (CCD) camera (Donohoe et al., 2006). Images of resin sections with thicknesses of $200-400 \mathrm{~nm}$ are recorded from $-60\left(-70^{\circ}\right)$ to $+60\left(+70^{\circ}\right)$ in $1-2^{\circ}$ angular increments to obtain an image stack containing 80-140 images. The generated images represent 1-4 $\mathrm{nm}$ thin slices (Donohoe et al., 2006). After recording the tilted images from the section, the grid is rotated $90^{\circ}$, and a second tilt series is acquired. Because tilting the specimen in single-axis tomography provides the so-called missing-wedge information, dual-axis ET analysis can complement the missed high-tilt projection data in single-axis ET. The obtained image stack can be processed and surface-rendered by $3 \mathrm{D}$ image processing software to obtain a virtual $3 \mathrm{D}$ volume; the method thus provides detailed information and contributes to our understanding of the overall 3D architecture of the cell (Mastronarde, 1997; McIntosh et al., 2005). This technique has been widely used to reveal the important features of cellular organelles (Otegui et al., 2001, 2006; Otegui and Staehelin, 2004; Seguí-Simarro et al., 2004; Shimoni et al., 2005; Austin et al., 2006; Leitz et al., 2009; Kang et al., 2011; Kowalewska et al., 2016). However, due to the thickness limitation, electron tomography based on transmission electron microscopy is not applicable to structures with large volumes, such as mitochondria and chloroplasts. Data collection from serial thick sections (serial ET) can solve this problem; however, similar to serial sectioning, this approach is timeconsuming, and the preparation of high-quality serial sections requires highly skilled staff. The limited range of tilting angles also makes the recording of overall structural data impossible.

Other powerful 3D imaging technologies, such as SBF-SEM and FIB-SEM, which is also known as focused ion beam-field emission scanning electron microscopy (FIB-FESEM), have the additional advantage of making it possible to reconstruct largevolume structures and can be used to overcome the thickness limitations of ET. With SBF-SEM and FIB-SEM, sectioning is performed automatically inside the SEM microscope using a diamond knife or a focused ion beam. After sectioning or milling, the freshly exposed block face is tilted vertically toward the electron beam for imaging (Romero-Brey and Bartenschlager, 2015). Hence, SBF/FIB-SEM comprehensively utilizes diamond knife/ion and electron beams to "slice and view" a set of images that can be used to generate 3D volumes. SBF-SEM and FIB-SEM are more suitable than ET for the $3 \mathrm{D}$ reconstruction of mesoscale structures, providing fine structural details while considering the links between the target structures (Marko et al., 2007; Drobne et al., 2008; Rigort et al., 2012; Kizilyaprak et al., 2014a,b; Rigort and Plitzko, 2015). In SBF-SEM and FIB-SEM, serial block-face imaging, sectioning and imaging of the sample are automatic; the use of these methods thus avoids many of the problems associated with manual sectioning. The numbers of the images depend on the Z-depth of desired volume and the Z-resolution is defined by the thickness of the slices. In comparison to SBF-SEM, the slice thickness is developed to $3 \mathrm{~nm}$ in FIB-SEM, whereas the minimum slice thickness is about $25 \mathrm{~nm}$ in SBF-SEM with optimal specimen. Hence, the main advantages of FIB-SEM over SBF-SEM are a significant improvement in $\mathrm{z}$-axis resolution. Moreover, FIB-SEM enables targeting a small region of interest without destroying the remainder of the block face, allowing the rest of the block face to be used for subsequent resampling (Arkill et al., 2014; Peddie and Collinson, 2014). Hence, FIBSEM has been widely used in the study of structures in virusinfected cells (Bennett et al., 2009; Felts et al., 2010; Do et al., 2014; Gómezaix et al., 2015). However, because the block face of the sample is destroyed during either FIB-SEM or SBF-SEM analyses, these methods cannot be used when it is necessary to retain the samples.

In recent years, cryo-ET has become a rapidly developing technology that offers high resolution. Unlike cryo-EM, which relies on symmetrical targets to generate $3 \mathrm{D}$ images and has been used for several decades to image viral structures, cryoET provides a way to image irregular structures in samples prepared by cryo-methods, and it can maintain samples in a considerably more native state than can be achieved using chemical fixation. Additionally, with recent advances in camera technology, cryo-ET now offers resolution at the molecular level. The use of cryo-ET in the visualization of virus replication factories has revealed several previously unrecognized features of these structures during TEM and ET analyses. However, 
the maximal thickness of the samples used in cryo-ET is $1 \mu \mathrm{m}$, which restricts its application in resolving structures with large volumes (Cyrklaff et al., 2007; Ertel et al., 2017). At present, ET and FIB-SEM are the most widely used methods in the study of the structures of animal and plant virus replication factories (Laliberté and Zheng, 2014; Risco et al., 2014; Harak and Lohmann, 2015; Fernández de Castro et al., 2017). The characteristics and advantages of various 3D electron microscopic techniques have been accurately summarized in recent reviews, and the protocols used for sample preparation can be found in specialized publications (Kuo, 2007; Zárský and Cvrčková, 2014; Romero-Brey and Bartenschlager, 2015).

\section{D ARCHITECTURE OF PLANT (+) RNA VIRUS REPLICATION FACTORIES}

Viral replication factories are derived from a variety of organelles, and the selection of organelles for building the replication factories depends on the virus. These organelles include the endoplasmic reticulum (ER), peroxisomes, mitochondria, chloroplasts, and tonoplasts (Verchot, 2011). Interestingly, the membranes responsible for the formation of replication factories of a virus may change, and viruses can use multiple organelles for replication (Xu and Nagy, 2014). For example, tomato bushy stunt virus (TBSV) utilizes peroxisomes to establish replication compartments. However, in yeast mutants in which peroxisome biogenesis is defective, TBSV replication sites are derived from the ER, which provides an optional subcellular membrane for virus replication (Jonczyk et al., 2007; Chuang et al., 2014). Similarly, when the targeting of flock house virus (FHV) replication protein A was changed from mitochondria to the ER, protein A was still capable of inducing membrane alterations and supporting FHV replication (Miller et al., 2003), suggesting that there is flexibility in the selection of organelles for building viral replication factories under different conditions. Despite their origins in different organelles, the 3D structures of numerous $(+)$ RNA virus replication factories reveal morphological similarities among different virus families. These similarities are manifested by two morphotypes. One morphotype is characterized by the formation of invaginated spherules with neck-like channels that connect the interior of the spherule to the cytoplasm. The second morphotype is characterized by the presence of single and/or double-membrane vesicles (SMVs or DMVs) that are formed by the remodeling of endomembranes (den Boon et al., 2010; Paul and Bartenschlager, 2013). It is worth noting that a new type of structure termed "appressed double-membrane layers" appeared when the expression ratio of brome mosaic virus (BMV) replication proteins was altered; these structures also supported BMV replication (Schwartz et al., 2004).

Since Kopek et al. reported the first 3D architecture of the membrane-bound (+) RNA viral replication compartments in FHV-infected Drosophila cells (Kopek et al., 2007), several 3D models of cellular remodeling during plant virus infection have been characterized. These are summarized in the following subsections.

\section{Beet Black Scorch Virus (BBSV)}

Alpha- and beta-necroviruses usually undergo replication on membranes derived from the ER or from tonoplasts (Kassanis et al., 1970; Appiano and Redolfi, 1993; Lot et al., 1996). BBSV, a Betanecrovirus in the Tombusviridae family, has a single-stranded RNA genome of positive polarity (Cao et al., 2002; Yuan et al., 2006). The genomic RNA of BBSV contains six open reading frames. Two of the encoded proteins are p23 and p82. p23 is an auxiliary replication protein, and p82 is a read-through product of p23 that possesses RNA-dependent RNA polymerase activity. Both proteins localize to the ER and are essential for the assembly of virus replication factories (Cao et al., 2015). In BBSV-infected Nicotiana benthamiana leaves, the ER aggregates to form punctate structures that can be observed by confocal laser scanning microscopy (CLSM) (Cao et al., 2015). These punctate structures or aggregates are thought to be associated with viral replication. TEM analysis further revealed the dilation, proliferation, and convolution of ER membranes (Figure 1A) and the formation of vesicle packets (VPs) along the ER (Figure 1B) or in the perinuclear cytoplasmic region (Cao et al., 2015). These rearranged membranous structures are likely the punctate structures observed by CLSM. In 2015, Cao et al. used ET to develop the first 3D model of an ER-associated replication compartment of a plant (+) RNA virus (Cao et al., 2015). These researchers' proposed $3 \mathrm{D}$ model shows the presence of one to several hundreds of spherules $50-70 \mathrm{~nm}$ in diameter in the interior of the VPs (Figures 1C-E). Viral double-stranded RNA (dsRNA), which is a genome replicative intermediate, and the replication protein p23 are both localized within the spherules, suggesting that these structures are sites of BBSV replication (Cao et al., 2015). BBSV spherules are arranged along the VP membranes, and most of them have a narrow neck connecting the spherule interior to the cytoplasm (Figures 1C-E), suggesting that they are formed from the invagination of ER membranes (Cao et al., 2015). Three animal viruses, dengue virus (DENV), Zika virus (ZIKV), and West Nile virus (WNV), all of which replicate on ER-derived membranes, also induce the formation of convoluted membranes (CMs) and/or VPs, and their replication occurs within membrane invaginations that originate from the ER and have openings to the cytosol (Welsch et al., 2009; Gillespie et al., 2010; Cortese et al., 2017). Surprisingly, in severe acute respiratory syndrome coronavirus (SARS-CoV)-infected cells, the inner vesicles in VPs show no pore connections to the outside (Knoops et al., 2008). Similar invaginations have been reported in the replication factories of other animal viruses such as FHV and Semliki Forest virus (SFV), although the replication factories of those viruses are derived from the mitochondrial membrane and the plasma membrane, respectively (Kopek et al., 2007; Kallio et al., 2013). However, pores interconnecting individual vesicles within the VPs of WNV are not observed in BBSV-induced spherules (Gillespie et al., 2010). Intriguingly, the VPs induced by BBSV are connected to each other by tubule-like structures 15$30 \mathrm{~nm}$ in diameter; such structures are rarely observed in other virus-induced membrane rearrangements (Cao et al., 2015). In addition, the putative viral RNAs of BBSV are observed as fibrillar materials with diverse morphologies, and these materials differ from those of WNV in their spatial distribution (Cao et al., 2015). 


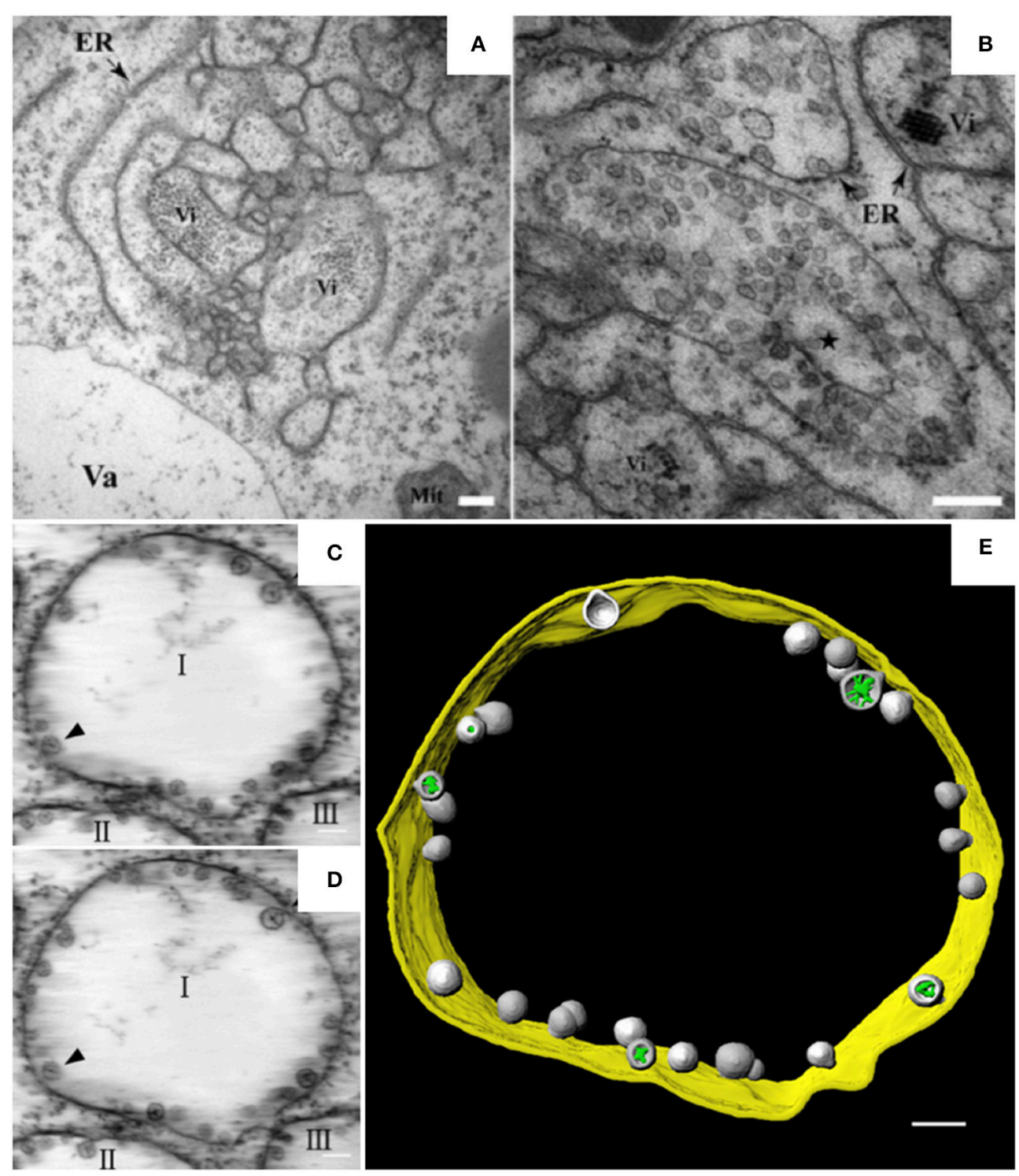

FIGURE 1 | BBSV remodels ER membranes and 3D model of BBSV-induced vesicle packets. (A) BBSV infection led to ER aggregation and vesiculation. (B) Vesicle packets were observed in the aggregates of branched ER cisternae (star). (C,D) Slices from the electron tomogram of BBSV-induced vesicle packets and spherules derived from ER. Arrowheads indicate the same spherules in different slices. The spherules are connected to the outer ER membrane. (E) Three-dimensional model of BBSV-induced vesicle packets and spherules derived from ER. Vi, virus particles or virus crystals; Va, vacuole; gold, vesicle packet derived from ER outer membrane; gray, spherules; green, fibrillar materials within the spherules. This figure is adapted with permission from Cao et al. (2015) (๑ 2015 by the American Society for Microbiology).

In summary, it is obvious that the ER is commonly hijacked as a platform for the formation of viral replication bodies, although the morphologies of the replication sites differ (Romero-Brey and Bartenschlager, 2016).

\section{Tomato Bushy Stunt Virus (TBSV)}

Most of the plant viruses that have been reported to build their replication factories on peroxisomes belong to the family Tombusviridae. TBSV is a well-studied (+) RNA virus in the genus Tombusvirus in the family Tombusviridae. During TBSV infection, the peroxisomal boundary membranes become progressively vesicular, leading to the formation of doughnutor C-shaped multivesicular bodies (MVBs), the interiors of which contain many single-membrane vesicle-like structures $80-150 \mathrm{~nm}$ in diameter. These vesicles appear to be connected to the MVB boundary membrane through a neck (Martelli et al., 1988; McCartney et al., 2005), and they provide the sites for TBSV replication (Appiano et al., 1984; Martelli et al., 1988; McCartney et al., 2005; Barajas et al., 2014a). MVBs are frequently observed in close association with the ER. Since some membranous materials used in the vesiculation of peroxisomes are derived from the ER (Martelli et al., 1988), this may explain 
TBSV's ability to utilize the ER for VRC assembly in the absence of peroxisomes (Jonczyk et al., 2007; Chuang et al., 2014). To better characterize the fine structure of TBSV replication factories and the distribution of viral replication proteins, metal-tagging transmission electron microscopy (METTEM) and $3 \mathrm{D}$ molecular mapping were used to reconstruct the TBSV replication platform in wild-type yeast (Figure 2A) and in a yeast strain in which a gene encoding phosphatidate phosphatase (pah1) was deleted (Figure 2B; Fernández de Castro et al., 2017). The absence of pah1 in yeast induces the proliferation and expansion of ER membranes. Interestingly, TBSV replicates more efficiently in $\Delta$ pah1 mutant yeast cells than in wildtype cells (Csaki and Reue, 2010; Chuang et al., 2014). 3D imaging shows that whereas the MVBs in TBSV-infected wildtype yeast cells consist of large numbers of spherules that are connected to the MVB boundary membrane, in $\Delta$ pah1 yeast cells, these vesicles are surrounded by and connected to the expanded ER membrane stacks instead of the peroxisomal MVB boundary membrane (Figures 2A,B). The architecture of the replication factories of TBSV in wild-type yeast is thus of the invaginated spherule type. METTEM analysis revealed that p33 is localized in both the MVBs and the ER, whereas viral dsRNA was only concentrated in the MVBs, suggesting that active RNA replication occurs in MVBs (Fernández de Castro et al., 2017). Because the biogenesis of peroxisomes involves ER membranes (Tabak et al., 2013), MVBs in $\Delta$ pah1 yeast are thought to be nascent peroxisomes that are defective for release from the ER (Fernández de Castro et al., 2017). In $\Delta p a h 1$ yeast, the attachment and connections of these vesicles to the ER creates a network that resembles the single network of interconnected membranes derived from the ER that is present in cells infected with flaviviruses, coronaviruses, or arteriviruses. The interconnected membranes ensure the rapid transport of translated viral proteins to the replication sites, suggesting a close link between viral protein translation and processing (Risco et al., 2014).

\section{Melon Necrotic Spot Virus (MNSV)}

MNSV belongs to the genus Carmovirus in the family Tombusviridae. Like TBSV and cymbidium ringspot virus (CymRSV), MNSV induces the formation of MVBs (Russo et al., 1983; McCartney et al., 2005; Fernández de Castro et al., 2017). However, unlike the MVBs of TBSV, the MVBs of MNSV originate from mitochondrial membranes (Burgyan et al., 1996). In MNSV-infected cells, mitochondrial structure is dramatically altered. For example, the mitochondrial matrix decreases in size or enlarges, forming dilations, and the periphery of the mitochondrial membrane becomes vesicular (Figure 3A). Singlemembrane vesicles $45-50 \mathrm{~nm}$ in diameter are formed along the mitochondrial membranes and around the large dilations inside the mitochondria. These vesicles appear to be connected to the cytoplasm or to the dilated lumen through neck-like structures (Gómezaix et al., 2015), as has been shown for FHV; viral infection thus induces mitochondria-derived invaginations with necks that are oriented toward the cytosol. Immunolocalization of MNSV (+) RNA, dsRNA, and CP revealed that these components are present in the large dilations of the altered mitochondria, suggesting that active MNSV replication occurs in the altered mitochondria and possibly in the numerous 50-nm vesicles (Gómezaix et al., 2015). 3D reconstruction of the mitochondria in MNSV-infected cells using FIB-FESEM reveals that these altered organelles possess many inner dilations that may be connected with each other (Figure 3B). These large dilations also have pores facing toward the outside cytoplasm that may be responsible for the exchange of materials required for viral replication. Although the vesiculation of the boundary membranes of replication organelles is similar to the vesiculation that occurs in many other viral infections,
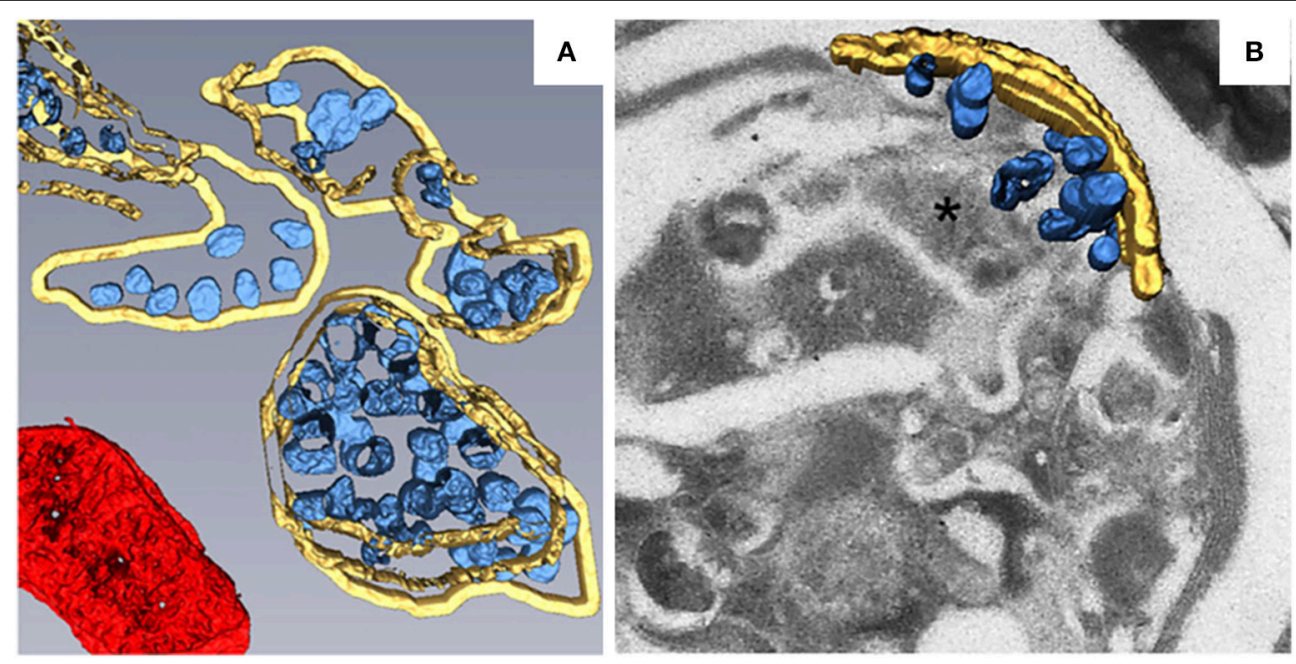

FIGURE 2 | 3D reconstruction of the TBSV replication platform in yeast. (A) 3D model of the TBSV replication platform in wild-type yeast cells characterized by peroxisome peripheral MVBs. Yellow, peripheral MVB membranes; blue, vesicle-like spherules; red, a mitochondrion. (B) 3D model of TBSV replication platform in $\Delta$ pah1 yeast cells characterized by a large membrane compartment (asterisk) containing MVB-like structures with spherules and stacked ER. Yellow, stacked ER membranes; blue, spherules. This figure is adapted with permission from Fernández de Castro et al. (2017) (@ 2017 by the Company of Biologists). 

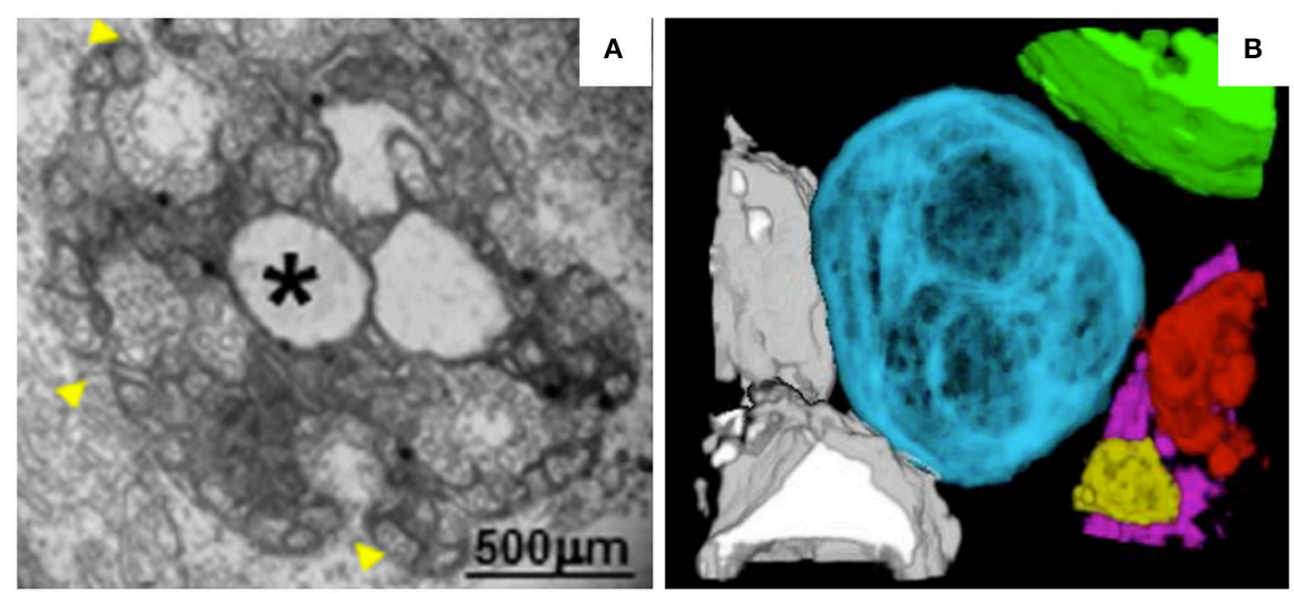

FIGURE 3 | TEM analysis and 3D reconstruction of MNSV-induced altered mitochondria. (A) TEM image showing altered mitochondria. Numerous vesicles were observed on the external surface as well as internal large invaginations and internal dilations (star), or both. Yellow arrowheads indicate the pores connecting the lumen of the dilation to the surrounding cytoplasm. (B) 3D model of MNSV-induced altered mitochondria with large dilations inside analyzed by FIB-FESEM. Connections between different mitochondria as well as with lipid bodies are observed. Blue, yellow, red, and purple indicate altered mitochondria; chloroplasts are shown in green and lipid bodies in gray. This figure is adapted with permission from Gómezaix et al. (2015) (๑ 2015 by the American Phytopathological Society).

the presence of surrounding vesicles that are connected to the large dilations within mitochondria is a distinct characteristic of MNSV infection. Moreover, the 3D structure of the replication organelles of MNSV reveals a striking similarity of MNSV replication factories to those of TBSV, in which the altered mitochondria are always associated with the ER, lipid bodies, or lipid droplets (LDs) (Figure 3B; Martin and Parton, 2005) and in close proximity to plasmodesmata. LDs are also observed in close proximity to the replication factories of numerous animal viruses (Miyanari et al., 2007; Fernández de Castro et al., 2014). The membranous structures induced by hepatitis $C$ virus (HCV) are primarily derived from the ER but also contain membranes derived from other compartments such as LDs that are important for HCV assembly. Hence, the connections between altered mitochondria and lipid bodies revealed by $3 \mathrm{D}$ reconstruction suggest a possible role of lipid bodies in MNSV replication, assembly, and other processes associated with viral infection.

\section{Turnip Mosaic Virus (TuMV)}

TuMV is a (+) RNA virus belonging to the genus Potyvirus in the family Potyviridae. TuMV replicates in ER-derived vesicles that are formed at endoplasmic reticulum exit sites (ERES), as evidenced by the accumulation of viral RNAs and replicationrelated proteins within these vesicles (Wei and Wang, 2008; Grangeon et al., 2012). Unlike the BBSV- and BMV-induced membrane invaginations of the ER (Schwartz et al., 2002; Cao et al., 2015), the ER-derived replicative vesicles of TuMV are motile and align with microfilaments (Cotton et al., 2009). A time-course TEM analysis of TuMV-infected cells revealed the sequential formation of ER-derived membranous structures characterized by CMs, single-membrane vesicle-like structures (SMVLs) (Figure 4A), double-membrane vesicle-like structures (DMVLs), and electron-dense bodies (Wan et al., 2015). The
CMs observed in TuMV-infected cells are similar to those induced by DENV, ZIKV, and SARS-CoV, which have been proposed to be the sites of viral polyprotein synthesis and processing (Knoops et al., 2008; Welsch et al., 2009; Cortese et al., 2017). 3D reconstruction of these membranous structures using ET indicated that the SMVLs and DMVLs observed in 2D TEM are in fact tubules (Figure 4B; Wan et al., 2015). Immunoelectron microscopic analyses of replication-related proteins showed specific labeling of membrane aggregates, and dsRNA was found to be specifically enriched in the singlemembrane vesicle tubules (SMTs), suggesting that the SMTs are the true sites at which TuMV replication occurs. SMTs are usually regularly arranged and associated with the rough ER (Figure 4B), and the 3D morphology of the electron-dense fibrillar material inside the SMTs is similar to that within BBSVinduced replicative spherules (Figure 4C; Cao et al., 2015). As the infection proceeds, the SMTs are transformed into doublemembrane vesicle tubules (DMTs) and intermediate tubular structures (Figure 4C). Interestingly, the SMTs and DMTs are similar to the membranous structures induced by coxsackievirus B3 and poliovirus, which are characterized by a transition from SMLs to DMLs during the course of virus infection. Likewise, in TuMV-, coxsackievirus B3-, and poliovirus-infected cells, DMLs with materials inside are formed by apposition, enwrapping, or fusion of SMTs (Limpens et al., 2011; Belov et al., 2012). Electron-dense bodies associated with virus-particle-like filament bundles are also formed at the late stage of infection, suggesting that virus particle assembly occurs there. At the final stages of infection, virus particles are found in the vacuoles, a location that might be favorable for aphid transmission of TuMV (Bak et al., 2017). ET analysis of TuMV-induced membranous structures at various time points during infection has thus made it possible to obtain a comprehensive overview of the changes that occur in endomembranes during the course of infection. 

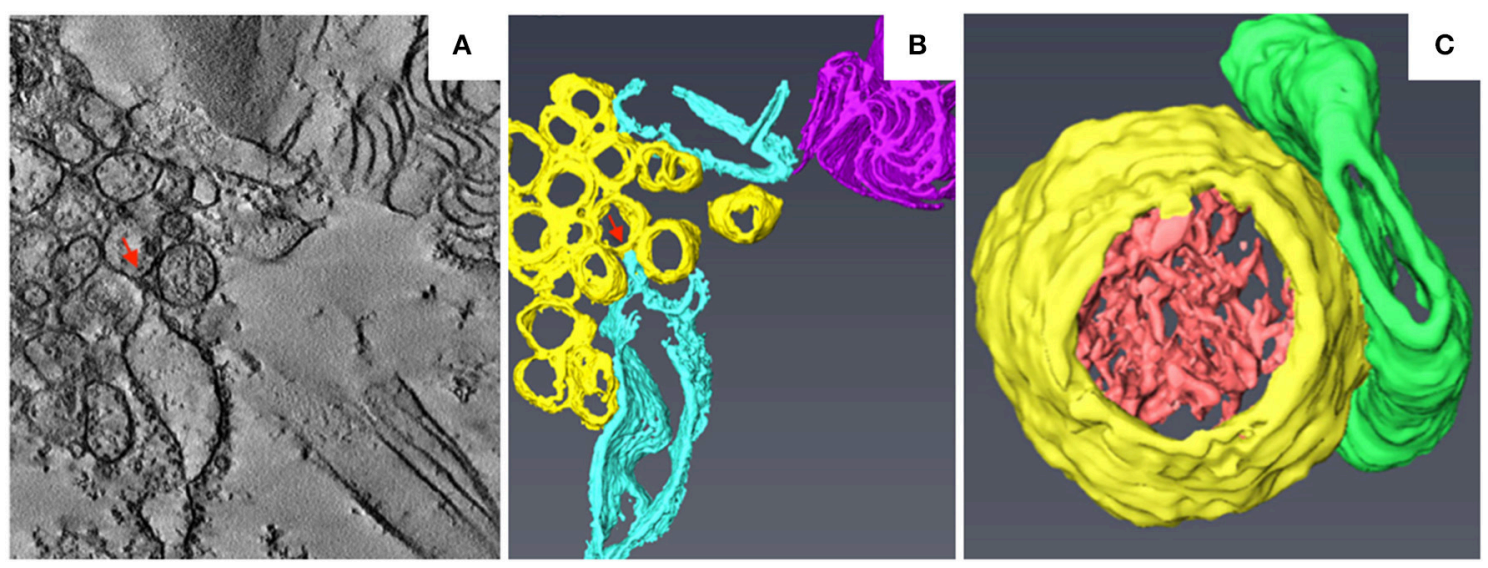

FIGURE 4 | 3D reconstruction of TuMV-induced SMTs at midstage of infection. (A) Tomogram slice from TuMV-infected vascular parenchymal cell. SMVL structures are seen in close proximity to dilated rER. (B) 3D surface rendering of TuMV-induced SMTs that connect with the rough ER. Yellow, SMTs; sky blue, rough ER; magenta, cytoplasmic inclusion body; red arrows, connection between the rough ER membrane and an SMT. (C) 3D model of the SMT with fibrillar materials inside. Yellow, SMTs; light red, electron-dense materials; green, intermediate tubular structures. This figure is adapted with permission from Wan et al. (2015) (@) 2015 by the American Society for Microbiology).

\section{Barley Stripe Mosaic Virus (BSMV)}

Barley stripe mosaic virus (BSMV) is the type member of the genus Hordeivirus in the family Virgaviridae (Jackson et al., 2009; Adams et al., 2017). The (+) strand RNA genome of BSMV encodes two replication proteins, $\alpha$ a and $\gamma$ a, which are localized in chloroplasts (Zhang et al., 2017). In BSMVinfected plants, the membranous structures of the chloroplasts change dramatically (Carroll, 1970; Lin and Langenberg, 1985; Torrance et al., 2006). Peripheral invaginations (Figures 5A,B) and large cytoplasmic invaginations (CIs) containing abundant virus-like particles (VLPs) are observed within the chloroplasts. Around the CI, similar invaginations are observed in which small spherules are occasionally observed (Figure 5A; Jin et al., 2018). Immunoelectron microscopy (IEM) indicates that viral dsRNA and the replication protein $\alpha$ a are specifically enriched in the invaginations at the periphery of the chloroplast envelope and the CIs, suggesting that BSMV replicates in these invaginations. ET was recently used to characterize the $3 \mathrm{D}$ architecture of chloroplast remodeling during BSMV infection. The generated model reveals that invaginations containing one or more spherules are formed from the chloroplast inner membrane (Figures 5A,B). These spherules, which have an internal diameter of $\sim 50 \mathrm{~nm}$, are generated from invaginations of the chloroplast outer membrane (Figure 5C). Each spherule has a neck that extends toward the cytoplasm, suggesting that these spherules are the true sites of BSMV replication (Figure 5C; Jin et al., 2018). The spherules around the CI also have necks that connect to the CI lumen, and IEM using serum containing antibodies against $\mathrm{CP}$ indicates that the virus-like particles (VLPs) inside the CI are BSMV virions. Thus, CI may be associated with the assembly of virus particles, and the existence of replicative spherules around the $\mathrm{CI}$ argues that the replication and assembly of BSMV are coupled processes. Furthermore, it was shown by FIB-SEM that the chloroplasts in BSMV-infected cells are extensively remodeled, as manifested by cavern-like invaginations with protrusions on their surfaces, and that CIs are surrounded by a double membrane and display irregular shapes with apertures of various sizes (Figures 5D,E). The replicative spherules of BSMV that are found between the chloroplast inner and outer membranes resemble the replication factories built by FHV (Kopek et al., 2007), and all of these spherules have openings to the cytoplasm. The CIs connected to the cytoplasm (Figures 5D,E) appear somewhat similar to the dilations within mitochondria induced by MNSV (Figures 3A,B), as evidenced by their outward connections and by the presence of peripheral spherules/vesicles.

In summary, despite having somewhat different morphologies, the replication factories built by plant $(+)$ RNA viruses belonging to different groups have many similarities, as do the replication factories produced by plant and animal viruses. In plants, the invaginated spherules/vesicles formed by negative membrane curvature are usually $50-150 \mathrm{~nm}$ in diameter and have neck-like connections to the cytoplasm. Like animal viruses, SMT and DMT structures induced by plant $(+)$ RNA viruses are highly motile and morphologically dynamic, implying that viral replication is tightly linked to particular stages of the viral infection cycle. Characterization of the $3 \mathrm{D}$ architectures of various membranous VRCs thus broadens our knowledge of the cellular structures that are formed during virus-host interaction and provides structural insight into the replication factories of $(+)$ RNA viruses. We also note that most of the currently available 3D tomograms of plant virus replication factories were generated from chemically fixed samples (Cao et al., 2015; Gómezaix et al., 2015; Fernández de Castro et al., 2017; Jin et al., 2018); such fixation may induce ultrastructural artifacts due to the slow diffusion of chemical fixatives and to selective cross-linking by chemical fixatives (Gilkey and Staehelin, 1986). Therefore, preparation of samples using cryo-methods should enable better preservation of the 

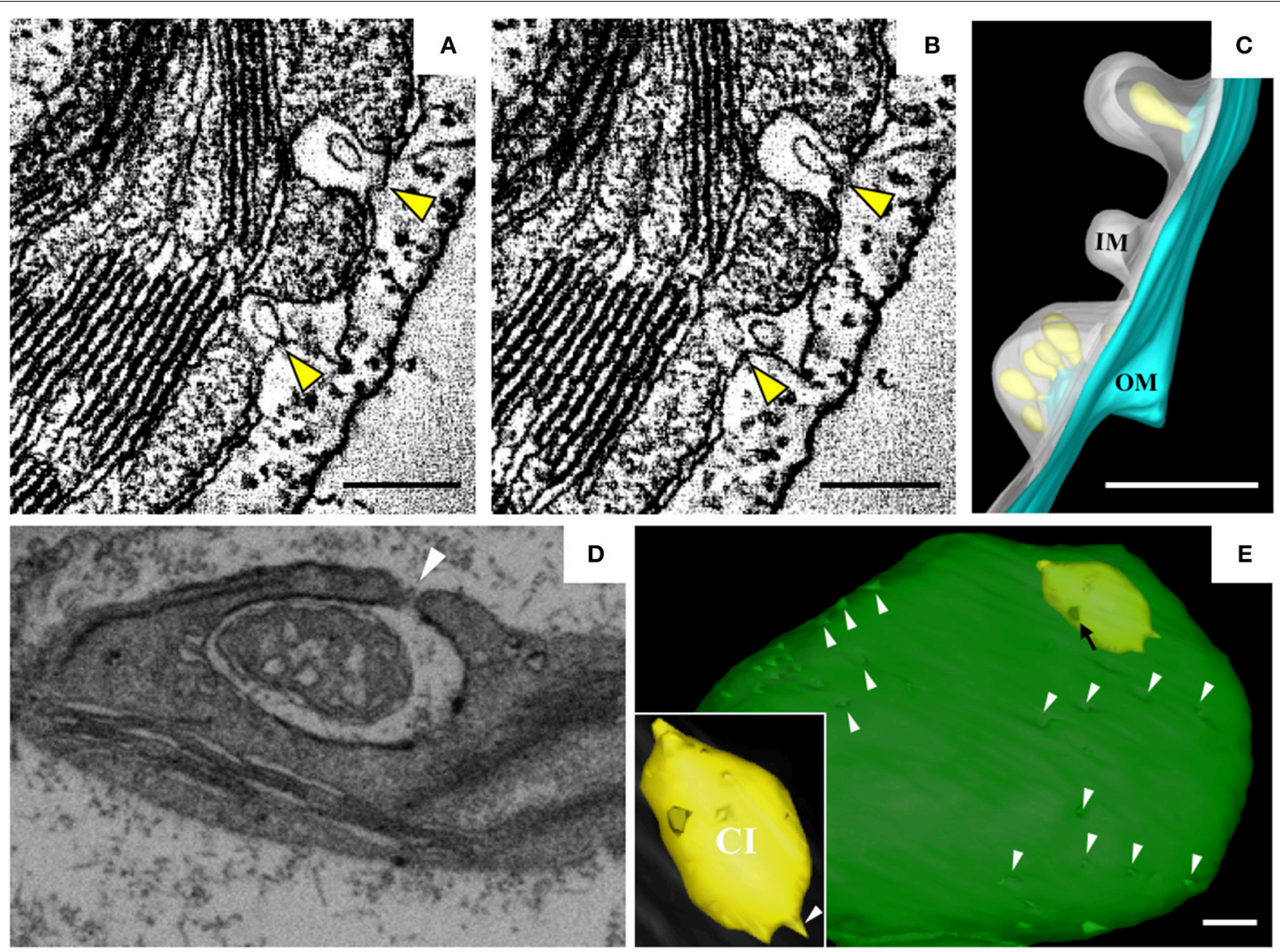

FIGURE 5 | BSMV-induced chloroplast membrane rearrangement and 3D model of altered chloroplast membranes. (A,B) Tomogram slices of altered chloroplast membranes from leaves of BSMV-infected $N$. benthamiana. The arrowheads indicate the same spherules in different slices. (C) 3D model of remodeled chloroplast membranes induced by BSMV. Light blue, outer chloroplast membrane (OM); translucent white, inner chloroplast membrane (IM); light yellow, spherules derived from the outer membrane. (D) Representative tomogram slice of remodeled chloroplast in BSMV-infected $N$. benthamiana leaves by FIB-SEM. The arrowhead indicates the opening of a Cl. (E) 3D visualization by FIB-SEM of a chloroplast in a BSMV-infected cell. Chl, chloroplast; Cl, cytoplasmic invagination; green, chloroplast; yellow, Cl; white arrowheads, chloroplast invaginations; black arrow, $\mathrm{Cl}$ aperture. The inset shows an enlarged view of a $\mathrm{Cl}$. This figure is adapted with permission from Jin et al. (2018) (๔ 2018 by the American Society of Plant Biologists).

native structure of the specimen and is expected to display the detailed ultrastructure of virus-infected plant cells more accurately.

\section{BIOGENESIS OF VIRAL REPLICATION COMPARTMENTS}

Virus-orchestrated membrane alterations leading to the production of replication factories depend on the action of one or more viral proteins (Paul and Bartenschlager, 2013; Laliberté and Zheng, 2014; Kovalev et al., 2016). These critical proteins are usually integral membrane proteins. They localize to a given organelle through their location signals or interact with membrane proteins or lipids and then initiate membrane bending. Although expression of these proteins alone may induce the formation of altered membranous structures similar to those found in virus-infected cells (Schwartz et al., 2002), in some cases the remodeled membranes induced by these proteins in the absence of virus differ from those observed during infection (Cao et al., 2015). Viral replication proteins are the major contributors to the alteration of endomembranes that occurs during virus infection. By localizing to the membrane, they also recruit other viral and host proteins or RNAs to the replication sites, leading to membrane deformation. The dynamic bending of the membranes is achieved mainly by the asymmetric interactions of proteins with the membrane and by local alterations in membrane lipid composition (McMahon and Gallop, 2005). The insertion of replication proteins into the membrane depends on their transmembrane domains or their amphipathic helices, and sometimes selfinteractions and interactions with lipids are equally important for generating and stabilizing membrane curvature. Moreover, the remodeling of the membrane involves diverse host factors, including membrane-shaping proteins and components of the early secretory pathway. We list some typical plant viral proteins and host factors that directly function in cellular remodeling in Table 1; below, we discuss some viruses that have been intensively studied in terms of the viral and host factors that are required for the production of their replication factories. 


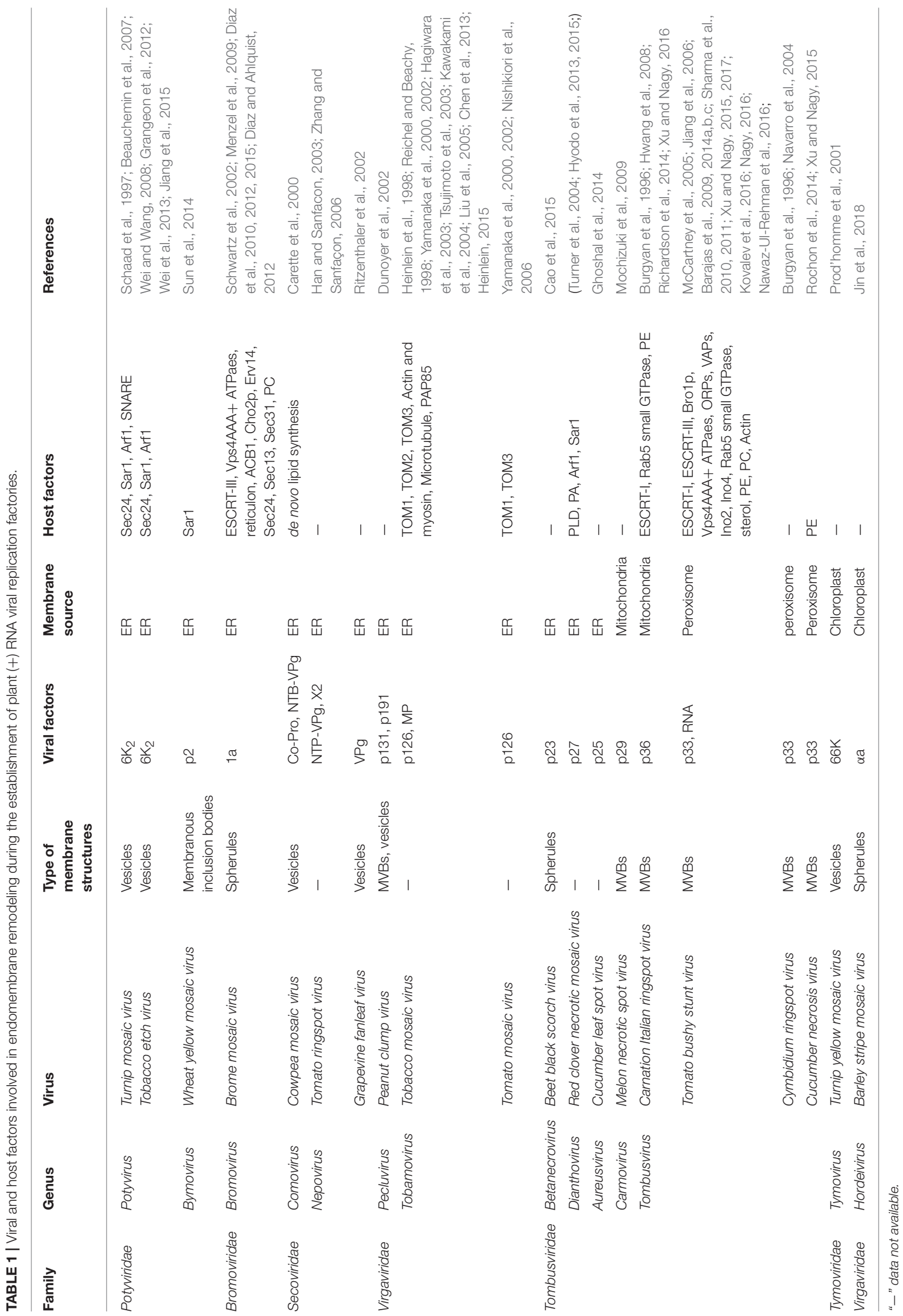




\section{Brome Mosaic Virus (BMV)}

$\mathrm{BMV}$ is one of the best-characterized $(+)$ RNA viruses in terms of its replication (Diaz and Wang, 2014). In plants, BMV replication is highly associated with the ER (Restrepo-Hartwig and Ahlquist, 1996). In yeast, expression of BMV replication proteins 1a and $2 \mathrm{a}$ and of RNA3 derivatives can also support BMV RNA replication (Janda and Ahlquist, 1993; Ishikawa et al., 1997); as in the plant host systems, proteins 1a and 2a target the ER for RNA synthesis, thereby duplicating the major features of BMV replication in plant cells (Restrepo-Hartwig and Ahlquist, 1999). Hence, yeast cells must contain the necessary factors for BMV replication. In plant cells, BMV infection induces the formation of ER-derived vesicular structures (Schwartz et al., 2002; Bamunusinghe et al., 2011). In yeast cells, BMVencoded replication protein 1a alone is capable of inducing the formation of ER-derived spherules associated with RNA synthesis. These ER-derived membranous structures are similar in appearance to those observed in BMV-infected plant cells (Schwartz et al., 2002). 1a has no transmembrane domain but instead contains an amphipathic $\alpha$-helix, helix $\mathrm{A}$, that is crucial for the protein's association with and subsequent rearrangement of membranes. In yeast, mutations within helix A lead to two distinct phenotypes that are characterized by the absence of membrane invaginations and the formation of abundant but smaller-sized spherules (Liu et al., 2009). Moreover, 1a selfinteractions involving the RNA capping and helicase domains are critical for the protein's association with the ER membrane and its ability to induce the formation of spherules (Liu et al., 2009; Diaz et al., 2012). Hence, when helix A inserts into the membrane, intramolecular and intermolecular interactions cause hundreds of $1 \mathrm{a}$ monomers to form an inner shell that induces the formation of $50-70 \mathrm{~nm}$ spherules. This is consistent with the high copy number of 1 a molecules in a spherule. Replication protein $2 \mathrm{a}$ also helps determine the conformation of BMV replication factories. Modulation of the relative expression levels of replication proteins $1 \mathrm{a}$ and $2 \mathrm{a}$ or disturbance of the interactions between them alters the morphology of the viral replication factories (Schwartz et al., 2004; Bamunusinghe et al., 2011).

The 1a protein also recruits some host factors that help increase the membrane curvature. Endosomal sorting complexes required for transport (ESCRT) proteins participate in sorting cargo proteins from the endosomes to MVBs through membrane invagination and vesicle formation; this process requires the sequential recruitment of ESCRT-0, ESCRT-I, II, III, and Vps4p, which generate membrane invaginations and subsequently direct membrane budding and scission (Wollert et al., 2009; Wollert and Hurley, 2010; Alonso et al., 2016). The production of BMV and of many other (+) RNA viruses, including the TBSVinduced spherules that will be discussed below, shares some topological similarities with the formation of ESCRT-dependent MVB vesicles and the budding of enveloped retroviruses. These replicative spherules are not released from the membrane and remain connected to it via a neck-like opening. The ESCRT-III effector Snf7p interacts strongly with BMV 1a and is recruited by 1 a to sites of viral replication. Deletion of Snf7p abolishes spherule formation and inhibits BMV replication, and deletion of other ESCRT-III factors such as Vps20p, Vps24p, and Vps2p modulates the number of spherules that are produced (Diaz et al., 2015). ESCRT-III factors have been proposed to function coordinately with cargo proteins in the limiting membranes, leading to membrane invagination. Although the interaction between 1a and ESCRT-III may facilitate 1a-induced membrane remodeling, it is not known how the replicative spherules avoid being released from the ER membrane or how they form closed vesicles. Another class of membrane-shaping proteins, reticulon homology proteins (RHPs), is needed for the formation of BMVs in the replication factory. RHPs comprise a family of membraneshaping proteins that function in the formation and stabilization of curved peripheral ER tubules (De Craene et al., 2006; Voeltz et al., 2006; Wakefield and Tear, 2006; Tolley et al., 2008); they are redistributed from ER tubules to BMV-induced replication compartments through interaction with BMV 1a (Diaz et al., 2010; Diaz and Ahlquist, 2012). EM analysis has indicated that complete deletion of RHPs abolishes spherule formation and viral replication and that their partial depletion results in the production of smaller-sized spherules. The fact that RHP participates in the formation of nuclear pores and modulates the size of the spherules suggests that it has a role in stabilizing the necks of the spherules (Diaz et al., 2010; Diaz and Ahlquist, 2012). Coat protein complex I (COPI) and COPII vesicles within the early secretory pathway for transporting proteins and lipids are also hijacked by BMV for 1a distribution (Beck et al., 2009; Brandizzi and Barlowe, 2013). A cargo receptor of COPII vesicles, the 14-kDa ER-vesicle protein Erv14, and the COPII coat component Sec24 are required for the recycling of BMV 1a from peripheral tubular ER to the perinuclear ER membrane. Deletion of Erv14 leads to decreased numbers of spherules and larger spherule size ( $\mathrm{Li}$ et al., 2016), suggesting that the interactions between 1a, Erv14 and Sec24 may facilitate the enrichment and self-interaction of $1 \mathrm{a}$, a necessary process for membrane remodeling and for the stabilization of spherules.

Replication factory membrane scaffolds are enriched in specific lipids that may be derived from existing lipid sources or synthesized de novo. Hence, viruses usually modulate host lipid metabolism in a way that favors the formation of replication factories. BMV infection is accompanied by the accumulation of lipids, indicating that these lipids participate directly or indirectly in BMV replication (Lee and Ahlquist, 2003). Recent investigations have shown that phosphatidylcholine (PC) accumulates at BMV replication sites though recruitment of the PC synthesis machinery by the 1a protein (Zhang et al., 2016). In addition, ACB1-encoded acyl coenzyme A (acyl-CoA) binding protein $(\mathrm{ACBP})$, a protein that promotes general lipid synthesis, is required for the assembly of replication factories (Zhang et al., 2012). Blocking PC synthesis leads to the formation of spherules with larger diameters, whereas deletion of ACBP leads to the production of a larger number of smaller spherules (Zhang et al., 2012, 2016). The morphology of the smaller spherules is similar to that of the spherules induced by the la mutant, suggesting that the formation of appropriate spherules requires interaction between 1a and lipids. Deletion of lipid synthesis genes or blockage of PC synthesis may lead to insufficient production of lipids for the formation of replication factories. Altered 
membrane lipid composition might further affect interactions between 1a and membranes; because hundreds of 1a proteins associate with the spherule's inner membrane to form a shelllike structure, the interaction of 1a with membrane lipids may regulate spherule size.

\section{Viruses in Tombusviridae}

The replication proteins of viruses in the Tombusviridae usually have a targeting signal; when expressed alone, these proteins can induce specific organelle membrane remodeling (Burgyan et al., 1996; Rubino and Russo, 1998; Navarro et al., 2004; McCartney et al., 2005; Panavas et al., 2005; Hwang et al., 2008; Mochizuki et al., 2009; Rochon et al., 2014; Gómezaix et al., 2015). Viral genomic RNAs also participate in the formation of the replication factory. Recent studies of tombusviruses have shown that spherule size correlates with the length of the viral RNA template (Kovalev et al., 2016). Similar results have also been reported for other animal viruses such as SFV and FHV (Kallio et al., 2013; Ertel et al., 2017). It is worthy of note that a recent cryo-ET study of FHV replication spherules revealed a novel crown-like structure surrounding the spherule's necked aperture (Ertel et al., 2017). This observation provides new insight into the export of viral progeny RNA from the spherules.

Replication proteins also recruit host factors that remodel membranes during the assembly of replication factories. Like BMV replication, TBSV replication can be reconstituted in yeast. Previous studies indicated that TBSV defective interfering (DI) RNA can replicate in yeast cells (Panavas and Nagy, 2003), and a cell-free system based on yeast supports the replication of full-length TBSV genomic RNA (Pogany and Nagy, 2008). In plant and yeast cells, both TBSV infection and repRNA replication induce the formation of peroxisome-derived MVBs; these spherule-like structures have necks that contact the peroxisome boundary membrane (McCartney et al., 2005; Barajas et al., 2014b; Fernández de Castro et al., 2017), suggesting evolutionary conservation of the selection of replication sites and VRC structures across different kingdoms. Hence, yeast has been developed as a surrogate model host for the study of TBSV replication and used to screen for host factors involved in TBSV replication (Nagy, 2008). Genome-wide screening using the TBSV-yeast model system indicates that seven ESCRT proteins are involved in the replication of TBSV (Jiang et al., 2006). TBSV recruits ESCRT proteins for membrane remodeling. Ubiquitinated TBSV p33 protein interacts with ESCRT-I Vps23p and its accessory ESCRT factor Brolp and then sequentially recruits the ESCRT-III machinery and Vps4 AAA+ ATPase to the replication sites to induce the formation of spherule-like structures (Li et al., 2008; Barajas et al., 2009, 2014a; Barajas and Nagy, 2010; Imura et al., 2015). Vps4 has also been identified as a component of the TBSV replication complex, and EM analysis of yeast cells infected by TBSV indicated that deletion of Vsp4 leads to the formation of crescent-like membrane structures that lack neck-like openings (Barajas et al., 2014a; Kovalev et al., 2016). Thus, a non-canonical role of Vps4 would be facilitation of the stabilization of neck structures of the TBSV-induced spherules and prevention of membrane scission. Similar results have also been reported for other tombusviruses. For instance,
CIRV recruits ESCRT-I protein to mitochondrion-derived VRCs through the p36 replication protein (Richardson et al., 2014). In addition, ESCRT factors also participate in the formation of BMV-induced spherules, as discussed above (Diaz et al., 2015). Hence, ESCRT factors are evolutionarily conserved host factors that are used by different viruses to promote spherule formation and to stabilize the neck-like structures of spherules.

Similar to the process that occurs during BMV infection, tombusvirus-induced membrane deformation requires lipid synthesis to support the huge proliferation of ER and peroxisome membranes (Sharma et al., 2011; Barajas et al., 2014c). Furthermore, sterols and phospholipids are enriched in the cellular locations at which TBSV RNA replication occurs in both plant cells and yeast (Sharma et al., 2010; Xu and Nagy, 2015, 2017). Sterols are essential membrane components that determine the curvature and fluidity of membranes (Lorizate and Kräusslich, 2011). The replication proteins p33 and p92 bind directly to sterols in vitro (Xu and Nagy, 2017). In addition, TBSV p33 interacts with oxysterol-binding ORP and VAMPassociated proteins (VAP), which mediate the redistribution of sterols to viral replication sites and facilitate the bending of membranes (Barajas et al., 2014b). The enrichment of sterols at viral replication sites in yeast cells may facilitate the efficient sequestration of replication proteins and may affect the topologies and structures of the replication proteins that remodel membranes. Large sterols might also maintain the stability of spherules for a longer time than that provided by ESCRTs. Phosphatidylethanolamine (PE) is the most abundant class of phospholipid at TBSV replication sites in yeast cells. Increases in PE levels as well as in phosphatidylcholine (PC) levels enhance TBSV RdRp activity, whereas increased phosphatidylglycerol (PG) levels have an inhibitory effect on TBSV replication (Xu and Nagy, 2015). Other tombusviruses, including cucumber necrosis tombusvirus (CNV) and CIRV, similarly induce the enrichment of PE in VRCs (Xu and Nagy, 2015). Further studies have shown that the enrichment of PE in TBSV replication factories is mediated by the direct interaction of the replication protein p33 with the endosomal Rab5 small GTPase, which leads to the redistribution of PE to viral replication sites (Xu and Nagy, 2016). $\mathrm{PE}$ is a cone-shaped lipid with a hydrophilic head and with a hydrophobic tail of varying length, and its enrichment can induce membrane curvature. The recruitment of PE to replication sites by p33 could facilitate membrane proliferation and spherule formation. The results of recent METTEM and 3D molecular mapping studies of TBSV-induced spherules in yeast cells show that the localization of $\mathrm{p} 33$ to an appropriate environment in which specific cofactors and lipids are present is a crucial step in viral replication (Fernández de Castro et al., 2017), substantiating the role of PE in supporting viral replication.

The cytoskeleton and motor proteins also play important roles in the formation and anchorage of viral replication complexes in plants. For example, recent studies indicate that the actin network is targeted by TBSV to support its replication. Confocal microscopy analysis showed that actin patches are closely associated with large p33-containing replication organelle-like structures in yeast cells and that such patches are present throughout the large replication compartments in plant cells, 
suggesting that actin plays a role in recruiting viral and cellular components (e.g., lipid) for VRC assembly (Nawaz-Ul-Rehman et al., 2016; Xu and Nagy, 2016). In addition, the formation and movement of TMV VRCs requires the involvement of the cytoskeleton (Heinlein et al., 1998; Kawakami et al., 2004; Liu et al., 2005). TMV $126-\mathrm{kD}$ protein regulates VRC size and facilitates the movement of VRCs along microfilaments (Liu et al., 2005). TMV-induced VRCs also contain viral movement protein (MP), which is targeted to the junctions of microtubules and ER (Martelli and Russo, 1977; Ashby et al., 2006; Sambade et al., 2008; Peiró et al., 2014). Furthermore, expression of MP alone leads to ER aggregation (Reichel and Beachy, 1998). The close association of MP with microtubules and ER strongly suggests that it plays a role in the formation of VRCs (Heinlein, 2015). Additional electron tomography of virus replication factories and the cytoskeletal network should be performed to determine their spatial relationships at high resolution and in three dimensions.

Red clover necrotic mosaic virus (RCNMV), another virus in Tombusviridae, promotes ER rearrangement for replication by inserting viral p27 into the membranes. Moreover, RCNMV hijacks the ADP ribosylation factor 1 (Arf1), a small GTPase involved in the formation of COPI vesicles within the early secretion pathway (Beck et al., 2009), to the viral replication sites (Hyodo et al., 2013). Dimerization of Arf1 is critical for positive membrane curvature during formation of coated vesicles (Beck et al., 2008; Krauss et al., 2008). The perturbation of ER morphology by p27 may depend on the interaction of p27 with Arf1 as well as its ability to bend membranes.

\section{Viruses in Potyviridae}

The $6 \mathrm{~K}_{2}$ protein of tobacco etch virus (TEV) and TuMV is an integral membrane protein that induces the formation of ERderived vesicles during infection (Schaad et al., 1997; Beauchemin et al., 2007; Cotton et al., 2009). Early secretory pathways have been found to play an extensive role in potyviral infection. Biogenesis of $6 \mathrm{~K}_{2}$ vesicles at ERES relies on the COPI and COPII machinery (Wei and Wang, 2008), and EM analysis showed a close association of bulging membranes and vesicles with the ER (Grangeon et al., 2012). Further studies indicated that the $6 \mathrm{~K}_{2}$ protein of TuMV interacts with the COPII coatomer Sec24a protein (Jiang et al., 2015) and that this interaction modifies the ER-Golgi interface and disrupts the protein secretion pathway. This block in protein and lipid transport between ER and Golgi may lead to the membrane aggregation and proliferation that is observed by EM (Wan et al., 2015). Functional disruption of Sec24a, Sar1, or the COPI component Arf1 protein compromises the formation of $6 \mathrm{~K}_{2}$ vesicles (Wei and Wang, 2008), supporting their role in membrane remodeling. The COPII protein Sar1 also interacts with the wheat yellow mosaic virus (WYMV) p2 protein, resulting in rearrangement of the ER during WYMV infection (Sun et al., 2014). Interestingly, the Golgi apparatus appears not to be affected during virus infection, suggesting that a Golgi bypass is possible. Recent studies have shown that unconventional secretory pathways are involved in the formation of MVBs (Ding et al., 2012).
The examples given above provide a good illustration of a common theme in membrane remodeling and the formation of spherules/vesicles: viral proteins, sometimes with the involvement of viral RNAs, recruit host factors that are diverted from their original functions and used to create virus replication factories (Diaz and Wang, 2014; Laliberté and Zheng, 2014; Wang, 2015; Nagy, 2016). However, further studies, especially studies of how these interactions correlate with and are mirrored by the 3D architecture of virus replication factories, are required. All of the $3 \mathrm{D}$ reconstructions of plant virus replication factories reported to date have been derived from wild-type virus-infected cells. However, little information regarding the $3 \mathrm{D}$ structure of the aberrant replication factories that are produced in response to the disruption of these interactions is available. In addition, the $3 \mathrm{D}$ spatial relationships between host factors and virus-induced membrane structures remain to be fully characterized.

\section{CONCLUSIONS AND FUTURE RESEARCH}

(+) RNA viruses replicate their genomes in association with the remodeling of cytoplasmic membranes. Advanced $3 \mathrm{D}$ imaging techniques enable the visualization and analysis of membrane morphologies in three dimensions. To date, $3 \mathrm{D}$ structures of the replication organelles of several plant viruses have been proposed, providing deeper insight into the assembly and biogenesis of virus replication factories. More and more host factors, such as the membrane-shaping and lipid synthesis-related proteins, have been shown to be involved in the formation of membranous replication factories. The results of these studies improve our understanding of the replication machinery in membrane compartments and provide new potential targets for the design of antiviral strategies.

Despite these recent advances, our current knowledge of the $3 \mathrm{D}$ architecture of (+) RNA virus replication factories is largely descriptive. There are still many issues that need to be addressed. For example, the dynamic changes that occur during virus-induced cellular remodeling, especially how viral and cellular components are transported into and out of replication factories, have not been thoroughly elucidated to date. A combination of live-cell imaging, correlative lightelectron microscopy, and new techniques for molecular probing would be helpful in determining the structural and dynamic aspects of viral replication factory biogenesis and its regulation in live cells and would be particularly useful for determining how cellular components interact with the virus to spatially and temporally regulate membrane remodeling during virus infection. It is fascinating to see how the $3 \mathrm{D}$ architectures of virus replication factories derived from different plant viruses or under various exogenous conditions directly reflect the molecular processes underlying viral replication. In addition, due to the tight coupling of viral replication with translation and viral particle assembly, how viruses utilize cellular membranous compartments to spatiotemporally coordinate different stages in the viral life cycle needs to be further addressed in the future. 
High-throughput profiling of purified viral replication factories should make it possible to determine their protein and lipid content, thereby providing a full view of the host constituents of viral replication factories and making it possible to decipher the mechanisms underlying virus-induced cellular remodeling. At the same time, virus-induced membrane curvature increases the surface area of the host endomembranes, which increases the likelihood of contact between different organelles. Recent studies have indicated that membrane contact sites (MCSs) play an important role in the communication between various organelles; this particularly applies to the ER, which contacts almost all other cellular organelles (Helle et al., 2013). It will be interesting to determine the function of MCSs in mediating the transport of host molecules to viral replication sites and how MCSs function in the perception of viral assault by the plant and thereby cause it to launch an antiviral response.

\section{REFERENCES}

Adams, M. J., Adkins, S., Bragard, C., Gilmer, D., Li, D., Macfarlane, S. A., et al. (2017). ICTV virus taxonomy profile: Virgaviridae. J. Gen. Virol. 98, 1999-2000. doi: 10.1099/jgv.0.000884

Alonso, Y. Adell, M., Migliano, S. M., and Teis, D. (2016). ESCRT-III and Vps4: a dynamic multipurpose tool for membrane budding and scission. FEBS J. 283, 3288-3302. doi: $10.1111 /$ febs. 13688

Appiano, A., and Redolfi, P. (1993). Ultrastructure and cytochemistry of phaseolus leaf tissues infected with an isolate of tobacco necrosis virus inducing localized wilting. Protoplasma 174, 116-127. doi: 10.1007/Bf01379043

Appiano, A., Bassi, M., and Dagostino, G. (1984). Cytochemical and autoradiographic observations on tomato bushy stunt virus-induced multivesicular bodies. Ultramicroscopy 12:162. doi: 10.1016/0304-3991(83)90450-3

Arkill, K. P., Qvortrup, K., Starborg, T., Mantell, J. M., Knupp, C., Michel, C. C., et al. (2014). Resolution of the three dimensional structure of components of the glomerular filtration barrier. BMC Nephrol. 15:24. doi: 10.1186/1471-2369-15-24

Ashby, J., Boutant, E., Seemanpillai, M., Sambade, A., Ritzenthaler, C., and Heinlein, M. (2006). Tobacco mosaic virus movement protein functions as a structural microtubule-associated protein. J. Virol. 80, 8329-8344. doi: 10.1128/JVI.00540-06

Austin, J. R. II., Frost, E., Vidi, P. A., Kessler, F., and Staehelin, L. A. (2006). Plastoglobules are lipoprotein subcompartments of the chloroplast that are permanently coupled to thylakoid membranes and contain biosynthetic enzymes. Plant Cell 18, 1693-1703. doi: 10.1105/tpc.105.039859

Bak, A., Cheung, A. L., Yang, C. L., Whitham, S. A., and Casteel, C. L. (2017). A viral protease relocalizes in the presence of the vector to promote vector performance. Nat. Commun. 8:14493. doi: 10.1038/ncomms14493C

Bamunusinghe, D., Seo, J.-K., and Rao, A. (2011). Subcellular localization and rearrangement of endoplasmic reticulum by brome mosaic virus capsid protein. J. Virol. 85, 2953-2963. doi: 10.1128/JVI.02020-10

Barajas, D., and Nagy, P. D. (2010). Ubiquitination of tombusvirus p33 replication protein plays a role in virus replication and binding to the host Vps23p ESCRT protein. Virology 397, 358-368. doi: 10.1016/j.virol.2009.11.010

Barajas, D., Jiang, Y., and Nagy, P. D. (2009). A unique role for the host ESCRT proteins in replication of tomato bushy stunt virus. PLoS Pathog. 5:e1000705. doi: 10.1371/journal.ppat.1000705

Barajas, D., Martín, I. F., Pogany, J., Risco, C., and Nagy, P. D. (2014a). Noncanonical role for the host Vps4 AAA+ ATPase ESCRT protein in the formation of tomato bushy stunt virus replicase. PLoS Pathog. 10:e1004087. doi: 10.1371/journal.ppat.1004087

\section{AUTHOR CONTRIBUTIONS}

$\mathrm{XJ}, \mathrm{YZ}, \mathrm{XC}, \mathrm{XW}, \mathrm{JJ}$, and JW wrote the manuscript. YZ and J-FL designed and revised the manuscript.

\section{ACKNOWLEDGMENTS}

We thank Drs. Dawei Li, Jialin Yu, Chenggui Han, Xianbing Wang, and Ying Wang at China Agricultural University for valuable discussions during the course of this work. This work was supported by grants from the National Natural Science Foundation of China (31470253 and 31100115), the Ministry of Agriculture of China (2016ZX08010-001), the Fundamental Research Funds for the Central Universities (2017SY003), and the Project for Extramural Scientists of SKLAB (2017SKLAB1$6)$. The authors apologize to all colleagues whose work could not be cited because of space limitations.
Barajas, D., Xu, K., De Castro Martin, I. F., Sasvari, Z., Brandizzi, F., Risco, C., et al. (2014b). Co-opted oxysterol-binding ORP and VAP proteins channel sterols to RNA virus replication sites via membrane contact sites. PLoS Pathog. 10:e1004388. doi: 10.1371/journal.ppat.1004388

Barajas, D., Xu, K., Sharma, M., Wu, C. Y., and Nagy, P. D. (2014c). Tombusviruses upregulate phospholipid biosynthesis via interaction between $\mathrm{p} 33$ replication protein and yeast lipid sensor proteins during virus replication in yeast. Virology 471, 72-80. doi: 10.1016/j.virol.2014.10.005

Baumeister, W. (2002). Electron tomography: towards visualizing the molecular organization of the cytoplasm. Curr. Opin. Struct. Biol. 12, 679-684. doi: 10.1016/S0959-440X(02)00378-0

Beauchemin, C., Boutet, N., and Laliberte, J. F. (2007). Visualization of the interaction between the precursors of VPg, the viral protein linked to the genome of turnip mosaic virus, and the translation eukaryotic initiation factor iso 4E in planta. J. Virol. 81, 775-782. doi: 10.1128/JVI.01277-06

Beck, R., Rawet, M., Wieland, F. T., and Cassel, D. (2009). The COPI system: molecular mechanisms and function. FEBS Lett. 583, 2701-2709. doi: 10.1016/j.febslet.2009.07.032

Beck, R., Sun, Z., Adolf, F., Rutz, C., Bassler, J., Wild, K., et al. (2008). Membrane curvature induced by Arf1-GTP is essential for vesicle formation. Proc. Natl. Acad. Sci. U.S.A. 105, 11731-11736. doi: 10.1073/pnas.0805 182105

Belov, G. A., Nair, V., Hansen, B. T., Hoyt, F. H., Fischer, E. R., and Ehrenfeld, E. (2012). Complex dynamic development of poliovirus membranous replication complexes. J. Virol. 86, 302-312. doi: 10.1128/jvi.05937-11

Bennett, A. E., Narayan, K., Shi, D., Hartnell, L. M., Gousset, K., He, H., et al. (2009). Ion-abrasion scanning electron microscopy reveals surface-connected tubular conduits in HIV-infected macrophages. PLoS Pathog. 5:e1000591. doi: 10.1371/journal.ppat.1000591

Brandizzi, F., and Barlowe, C. (2013). Organization of the ER-Golgi interface for membrane traffic control. Nat. Rev. Mol. Cell Biol. 14, 382-392. doi: $10.1038 / \mathrm{nrm} 3588$

Burgyan, J., Rubino, L., and Russo, M. (1996). The 5'-terminal region of a tombusvirus genome determines the origin of multivesicular bodies. J. Gen. Virol. 77, 1967-1974. doi: 10.1099/0022-1317-77-8-1967

Cao, X., Jin, X., Zhang, X., Li, Y., Wang, C., Wang, X., et al. (2015). Morphogenesis of endoplasmic reticulum membrane-invaginated vesicles during beet black scorch virus infection: role of auxiliary replication protein and new implications of three-dimensional architecture. J. Virol. 89, 6184-6195. doi: 10.1128/JVI.00401-15

Cao, Y., Cai, Z., Ding, Q., Li, D., Han, C., Yu, J., et al. (2002). The complete nucleotide sequence of beet black scorch virus (BBSV), a new member of the genus Necrovirus. Arch. Virol. 147, 2431-2435. doi: 10.1007/s00705-002-0896-1 
Carette, J. E., Stuiver, M., Van Lent, J., Wellink, J., and Van Kammen, A. (2000). Cowpea mosaic virus infection induces a massive proliferation of endoplasmic reticulum but not Golgi membranes and is dependent on de novo membrane synthesis. J. Virol. 74, 6556-6563. doi: 10.1128/JVI.74.14.6556-6563.2000

Carroll, T. W. (1970). Relation of barley stripe mosaic virus to plastids. Virology 42, 1015-1022. doi: 10.1016/0042-6822(70)90350-8

Chen, C. E., Yeh, K. C., Wu, S. H., Wang, H. I., and Yeh, H. H. (2013). A vicilin-like seed storage protein, PAP85, is involved in tobacco mosaic virus replication. J. Virol. 87, 6888-6900. doi: 10.1128/JVI.00268-13

Chuang, C., Barajas, D., Qin, J., and Nagy, P. D. (2014). Inactivation of the host lipin gene accelerates RNA virus replication through viral exploitation of the expanded endoplasmic reticulum membrane. PLoS Pathog. 10:e1003944. doi: 10.1371/journal.ppat.1003944

Cortese, M., Goellner, S., Acosta, E. G., Neufeldt, C. J., Oleksiuk, O., Lampe, M., et al. (2017). Ultrastructural characterization of Zika virus replication factories. Cell Rep. 18, 2113-2123. doi: 10.1016/j.celrep.2017.02.014

Cotton, S., Grangeon, R., Thivierge, K., Mathieu, I., Ide, C., Wei, T. Y., et al. (2009). Turnip mosaic virus RNA replication complex vesicles are mobile, align with microfilaments, and are each derived from a single viral genome. Commun. Integr. Biol. 83, 10460-10471. doi: 10.1128/JVI.00819-09

Csaki, L. S., and Reue, K. (2010). Lipins: multifunctional lipid metabolism proteins. Annu. Rev. Nutr. 30, 257-272. doi: 10.1146/annurev.nutr.012809.104729

Cyrklaff, M., Linaroudis, A., Boicu, M., Chlanda, P., Baumeister, W., Griffiths, G., et al. (2007). Whole cell cryo-electron tomography reveals distinct disassembly intermediates of vaccinia virus. PLOS ONE 2:e420. doi: 10.1371/journal.pone.0000420

De Craene, J. O., Coleman, J., Estrada De Martin, P., Pypaert, M., Anderson, S., Yates, J. R. III., et al. (2006). Rtnlp is involved in structuring the cortical endoplasmic reticulum. Mol. Biol. Cell 17, 3009-3020. doi: 10.1091/mbc.E06-01-0080

den Boon, J. A., Diaz, A., and Ahlquist, P. (2010). Cytoplasmic viral replication complexes. Cell Host Microbe 8, 77-85. doi: 10.1016/j.chom.2010.06.010

Diaz, A., and Ahlquist, P. (2012). Role of host reticulon proteins in rearranging membranes for positive-strand RNA virus replication. Curr. Opin. Microbiol. 15, 519-524. doi: 10.1016/j.mib.2012.04.007

Diaz, A., and Wang, X. (2014). Bromovirus-induced remodeling of host membranes during viral RNA replication. Curr. Opin. Virol. 9, 104-110. doi: 10.1016/j.coviro.2014.09.018

Diaz, A., Gallei, A., and Ahlquist, P. (2012). Bromovirus RNA replication compartment formation requires concerted action of 1a's self-interacting RNA capping and helicase domains. J. Virol. 86, 821-834. doi: 10.1128/JVI.05684-11

Diaz, A., Wang, X., and Ahlquist, P. (2010). Membrane-shaping host reticulon proteins play crucial roles in viral RNA replication compartment formation and function. Proc. Natl. Acad. Sci. U.S.A. 107, 16291-16296. doi: $10.1073 /$ pnas. 1011105107

Diaz, A., Zhang, J., Ollwerther, A., Wang, X., and Ahlquist, P. (2015). Host ESCRT proteins are required for Bromovirus RNA replication compartment assembly and function. PLoS Pathog. 11:e1004742. doi: 10.1371/journal.ppat.1004742

Ding, Y., Wang, J., Wang, J., Stierhof, Y.-D., Robinson, D. G., and Jiang, L. (2012). Unconventional protein secretion. Trends Plant Sci. 17, 606-615. doi: 10.1016/j.tplants.2012.06.004

Do, T., Murphy, G., Earl, L. A., Del Prete, G. Q., Grandinetti, G., Li, G. H., et al. (2014). Three-dimensional imaging of HIV-1 virological synapses reveals membrane architectures involved in virus transmission. J. Virol. 88, 10327-10339. doi: 10.1128/JVI.00788-14

Donohoe, B. S., Mogelsvang, S., and Staehelin, L. A. (2006). Electron tomography of ER, Golgi and related membrane systems. Methods 39, 154-162. doi: 10.1016/j.ymeth.2006.05.013

Drobne, D., Milani, M., Leser, V., Tatti, F., Zrimec, A., Znidarsic, N., et al. (2008). Imaging of intracellular spherical lamellar structures and tissue gross morphology by a focused ion beam/scanning electron microscope (FIB/SEM). Ultramicroscopy 108, 663-670. doi: 10.1016/j.ultramic.2007.10.010

Dunoyer, P., Ritzenthaler, C., Hemmer, O., Michler, P., and Fritsch, C. (2002). Intracellular localization of the peanut clump virus replication complex in tobacco BY-2 protoplasts containing green fluorescent proteinlabeled endoplasmic reticulum or Golgi apparatus. J. Virol. 76, 865-874. doi: 10.1128/JVI.76.2.865-874.2002
Ertel, K. J., Benefield, D., Castaño-Diez, D., Pennington, J. G., Horswill, M., Den Boon, J. A., et al. (2017). Cryo-electron tomography reveals novel features of a viral RNA replication compartment. eLife 6:e25940. doi: 10.7554/eLife.25940

Felts, R. L., Narayan, K., Estes, J. D., Shi, D., Trubey, C. M., Fu, J., et al. (2010). 3D visualization of HIV transfer at the virological synapse between dendritic cells and T cells. Proc. Natl. Acad. Sci. U.S.A. 107, 13336-13341. doi: 10.1073/pnas.1003040107

Fernández de Castro, I., Fernández, J. J., Barajas, D., Nagy, P. D., and Risco, C. (2017). Three-dimensional imaging of the intracellular assembly of a functional viral RNA replicase complex. J. Cell. Sci. 130, 260-268. doi: 10.1242/jcs.181586

Fernández de Castro, I., Zamora, P. F., Ooms, L., Fernandez, J. J., Lai, C. M. H., Mainou, B. A., et al. (2014). Reovirus forms neo-organelles for progeny particle assembly within reorganized cell membranes. MBio 5, e00931-e00913. doi: 10.1128/mBio.00931-13

Ghoshal, K., Theilmann, J., Reade, R., Sanfacon, H., and Rochon, D. (2014). The cucumber leaf spot virus p25 auxiliary replicase protein binds and modifies the endoplasmic reticulum via N-terminal transmembrane domains. Virology 468-470, 36-46. doi: 10.1016/j.virol.2014.07.020

Gilkey, J. C., and Staehelin, L. A. (1986). Advances in ultrarapid freezing for the preservation of cellular ultrastructure. J. Electron Microsc. Technol. 3, 177-210. doi: 10.1002/jemt.1060030206

Gillespie, L. K., Hoenen, A., Morgan, G., and Mackenzie, J. M. (2010). The endoplasmic reticulum provides the membrane platform for biogenesis of the flavivirus replication complex. J. Virol. 84, 10438-10447. doi: 10.1128/JVI.00986-10

Gómezaix, C., Garcíagarcía, M., Aranda, M. A., and Sánchezpina, M. A. (2015). Melon necrotic spot virus replication occurs in association with altered mitochondria. Mol. Plant Microbe Interact. 28, 387-397. doi: 10.1094/MPMI-09-14-0274-R

Grangeon, R., Agbeci, M., Chen, J., Grondin, G., Zheng, H., and Laliberté, J. F. (2012). Impact on the endoplasmic reticulum and Golgi apparatus of turnip mosaic virus infection. J. Virol. 86, 9255-9265. doi: 10.1128/JVI.01146-12

Hagiwara, Y., Komoda, K., Yamanaka, T., Tamai, A., Meshi, T., Funada, R., et al. (2003). Subcellular localization of host and viral proteins associated with tobamovirus RNA replication. EMBO J. 22, 344-353. doi: 10.1093/emboj/cdg033

Han, S., and Sanfacon, H. (2003). Tomato ringspot virus proteins containing the nucleoside triphosphate binding domain are transmembrane proteins that associate with the endoplasmic reticulum and cofractionate with replication complexes. J. Virol. 77, 523-534. doi: 10.1128/JVI.77.1.523-534.2003

Harak, C., and Lohmann, V. (2015). Ultrastructure of the replication sites of positive-strand RNA viruses. Virology 479, 418-433. doi: 10.1016/j.virol.2015.02.029

Heinlein, M. (2015). Plant virus replication and movement. Virology 479-480, 657-671. doi: 10.1016/j.virol.2015.01.025

Heinlein, M., Padgett, H. S., Gens, J. S., Pickard, B. G., Casper, S. J., Epel, B. L., et al. (1998). Changing patterns of localization of the tobacco mosaic virus movement protein and replicase to the endoplasmic reticulum and microtubules during infection. Plant Cell 10, 1107-1120. doi: 10.2307/3870715

Helle, S. C., Kanfer, G., Kolar, K., Lang, A., Michel, A. H., and Kornmann, B. (2013). Organization and function of membrane contact sites. Biochim. Biophys. Acta 1833, 2526-2541. doi: 10.1016/j.bbamcr.2013.01.028

Hwang, Y. T., Mccartney, A. W., Gidda, S. K., and Mullen, R. T. (2008). Localization of the carnation italian ringspot virus replication protein p36 to the mitochondrial outer membrane is mediated by an internal targeting signal and the TOM complex. BMC Cell Biol. 9:54. doi: 10.1186/1471-212 1-9-54

Hyodo, K., Mine, A., Taniguchi, T., Kaido, M., Mise, K., Taniguchi, H., et al. (2013). ADP ribosylation factor 1 plays an essential role in the replication of a plant RNA virus. J. Virol. 87, 163-176. doi: 10.1128/JVI.02383-12.

Hyodo, K., Taniguchi, T., Manabe, Y., Kaido, M., Mise, K., Sugawara, T., et al. (2015). Phosphatidic acid produced by phospholipase D promotes RNA replication of a plant RNA virus. PLoS Pathog. 11:e1004909. doi: 10.1371/journal.ppat.1004909

Imura, Y., Molho, M., Chuang, C., and Nagy, P. D. (2015). Cellular Ubc2/Rad6 E2 ubiquitin-conjugating enzyme facilitates tombusvirus replication in yeast and plants. Virology 484, 265-275. doi: 10.1016/j.virol.2015.05.022 
Ishikawa, M., Janda, M., Krol, M. A., and Ahlquist, P. (1997). In vivo DNA expression of functional brome mosaic virus RNA replicons in Saccharomyces cerevisiae. J. Virol. 71, 7781-7790.

Jackson, A. O., Lim, H. S., Bragg, J., Ganesan, U., and Mi, Y. L. (2009). Hordeivirus replication, movement, and pathogenesis. Annu. Rev. Phytopathol. 47, 385-422. doi: 10.1146/annurev-phyto-080508-081733

Janda, M., and Ahlquist, P. (1993). RNA-dependent replication, transcription, and persistence of brome mosaic virus RNA replicons in S. cerevisiae. Cell 72, 961-970.

Jiang, J., Patarroyo, C., Cabanillas, D. G., Zheng, H., and Laliberté, J. F. (2015). The vesicle-forming $6 \mathrm{~K} 2$ protein of turnip mosaic virus interacts with the COPII coatomer Sec24a for viral systemic infection. J. Virol. 89, 6695-6710. doi: 10.1128/JVI.00503-15

Jiang, Y., Serviene, E., Gal, J., Panavas, T., and Nagy, P. D. (2006). Identification of essential host factors affecting tombusvirus RNA replication based on the yeast Tet promoters Hughes collection. J. Virol. 80, 7394-7404. doi: 10.1128/JVI.02686-05

Jin, X., Jiang, Z., Zhang, K., Wang, P., Cao, X., Yue, N., et al. (2018). Threedimensional analysis of chloroplast structures associated with virus infection. Plant Physiol. 176, 282-294. doi: 10.1104/pp.17.00871

Jonczyk, M., Pathak, K. B., Sharma, M., and Nagy, P. D. (2007). Exploiting alternative subcellular location for replication: tombusvirus replication switches to the endoplasmic reticulum in the absence of peroxisomes. Virology 362, 320-330. doi: 10.1016/j.virol.2007.01.004

Kallio, K., Hellstrom, K., Balistreri, G., Spuul, P., Jokitalo, E., and Ahola, T. (2013). Template RNA length determines the size of replication complex spherules for Semliki Forest virus. J. Virol. 87, 9125-9134. doi: 10.1128/JVI.00660-13

Kang, B.-H., Nielsen, E., Preuss, M. L., Mastronarde, D., and Staehelin, L. A. (2011). Electron tomography of RabA4b- and PI-4K $\beta 1$-labeled trans Golgi network compartments in Arabidopsis. Traffic 12, 313-329. doi: 10.1111/j.1600-0854.2010.01146.x

Kassanis, B., Vince, D. A., and Woods, R. D. (1970). Light and electron microscopy of cells infected with tobacco necrosis and satellite viruses. J. Gen. Virol. 7, 143-151. doi: 10.1099/0022-1317-7-2-143

Kawakami, S., Watanabe, Y., and Beachy, R. N. (2004). Tobacco mosaic virus infection spreads cell to cell as intact replication complexes. Proc. Natl. Acad. Sci. U.S.A. 101, 6291-6296. doi: 10.1073/pnas.0401221101

Kizilyaprak, C., Bittermann, A. G., Daraspe, J., and Humbel, B. M. (2014a). FIB-SEM tomography in biology. Methods Mol. Biol. 1117, 541-558. doi: 10.1007/978-1-62703-776-1_24

Kizilyaprak, C., Daraspe, J., and Humbel, B. M. (2014b). Focused ion beam scanning electron microscopy in biology. J. Microsc. 254, 109-114. doi: $10.1111 /$ jmi.12127

Knoops, K., Kikkert, M., Van Den Worm, S. H. E., Zevenhoven-Dobbe, J. C., Van Der Meer, Y., Koster, A. J., et al. (2008). SARS-coronavirus replication is supported by a reticulovesicular network of modified endoplasmic reticulum. PLoS Biol. 6:e226. doi: 10.1371/journal.pbio.0060226

Kopek, B. G., Perkins, G., Miller, D. J., Ellisman, M. H., and Ahlquist, P. (2007). Three-dimensional analysis of a viral RNA replication complex reveals a virusinduced mini-organelle. PLoS Biol. 5:e220. doi: 10.1371/journal.pbio.0050220

Kovalev, N., De Castro Martin, I. F., Pogany, J., Barajas, D., Pathak, K., Risco, C., et al. (2016). Role of viral RNA and co-opted cellular ESCRT-I and ESCRTIII factors in formation of tombusvirus spherules harboring the tombusvirus replicase. J. Virol. 90, 3611-3626. doi: 10.1128/JVI.02775-15

Kowalewska, Ł., Mazur, R., Suski, S., Garstka, M., and Mostowska, A. (2016). Three-dimensional visualization of the tubular-lamellar transformation of the internal plastid membrane network during runner bean chloroplast biogenesis. Plant Cell 28, 875-891. doi: 10.1105/tpc.15.01053

Krauss, M., Jia, J. Y., Roux, A., Beck, R., Wieland, F. T., De Camilli, P., et al. (2008). Arf1-GTP-induced tubule formation suggests a function of Arf family proteins in curvature acquisition at sites of vesicle budding. J. Biol. Chem. 283, 27717-27723. doi: 10.1074/jbc.M804528200

Kuo, J. (2007). Electron Microscopy: Methods and Protocols. New York, NY: Springer Science \& Business Media.

Laliberté, J. F., and Zheng, H. (2014). Viral manipulation of plant host membranes. Annu. Rev. Virol. 1, 237-259. doi: 10.1146/annurev-virology-031413-085532

Lee, W. M., and Ahlquist, P. (2003). Membrane synthesis, specific lipid requirements, and localized lipid composition changes associated with a positive-strand RNA virus RNA replication protein. J. Virol. 77, 12819-12828. doi: 10.1128/JVI.77.23.12819-12828.2003

Leitz, G., Kang, B. H., Schoenwaelder, M. E., and Staehelin, L. A. (2009). Statolith sedimentation kinetics and force transduction to the cortical endoplasmic reticulum in gravity-sensing Arabidopsis columella cells. Plant Cell 21, 843-860. doi: $10.1105 /$ tpc.108.065052

Li, J., Fuchs, S., Zhang, J., Wellford, S., Schuldiner, M., and Wang, X. (2016). An unrecognized function for COPII components in recruiting a viral replication protein to the perinuclear ER. J. Cell. Sci. 129, 3597-3608. doi: $10.1242 /$ jcs. 190082

Li, Z., Barajas, D., Panavas, T., Herbst, D. A., and Nagy, P. D. (2008). Cdc34p ubiquitin-conjugating enzyme is a component of the tombusvirus replicase complex and ubiquitinates p33 replication protein. J. Virol. 82, 6911-6926. doi: 10.1128/JVI.00702-08

Limpens, R. W., Van Der Schaar, H. M., Kumar, D., Koster, A. J., Snijder, E. J., Van Kuppeveld, F. J., et al. (2011). The transformation of enterovirus replication structures: a three-dimensional study of single- and double-membrane compartments. MBio 2, e00166-e00111. doi: 10.1128/mBio.00166-11

Lin, N. S., and Langenberg, W. G. (1985). Peripheral vesicles in proplastids of barley stripe mosaic virus-infected wheat cells contain double-stranded RNA. Virology 142, 291-298. doi: 10.1016/0042-6822(85)90337-X

Liu, J. Z., Blancaflor, E. B., and Nelson, R. S. (2005). The tobacco mosaic virus 126-kilodalton protein, a constituent of the virus replication complex, alone or within the complex aligns with and traffics along microfilaments. Plant Physiol. 138, 1853-1865. doi: 10.1104/pp.105.065722

Liu, L., Westler, W. M., Den Boon, J. A., Wang, X., Diaz, A., Steinberg, H. A., et al. (2009). An amphipathic alpha-helix controls multiple roles of brome mosaic virus protein 1a in RNA replication complex assembly and function. PLoS Pathog. 5:e1000351. doi: 10.1371/journal.ppat.1000351

Lorizate, M., and Kräusslich, H. G. (2011). Role of lipids in virus replication. Cold Spring Harb. Perspect Biol. 3:a004820. doi: 10.1101/cshperspect.a004820

Lot, H., Rubino, L., Delecolle, B., Jacquemond, M., Turturo, C., and Russo, M. (1996). Characterization, nucleotide sequence and genome organization of Leek white stripe virus, a putative new species of the genus Necrovirus. Arch. Virol. 141, 2375-2386. doi: 10.1007/BF01718638

Marko, M., Hsieh, C., Schalek, R., Frank, J., and Mannella, C. (2007). Focusedion-beam thinning of frozen-hydrated biological specimens for cryo-electron microscopy. Nat. Methods 4, 215-217. doi: 10.1038/nmeth1014

Martelli, G. P., and Russo, M. (1977). Plant virus inclusion bodies. Adv. Virus Res. 21, 175-266.

Martelli, G. P., Gallitelli, D., and Russo, M. (1988). “Tombusviruses,” in The Plant Viruses. Polyhedral Virions with Monopartite RNA Genomes, ed R. Koenig (New York, NY: Plenum Press), 13-72.

Martin, S., and Parton, R. G. (2005). Caveolin, cholesterol, and lipid bodies. Semin. Cell Dev. Biol. 16, 163-174. doi: 10.1016/j.semcdb.2005.01.007

Mastronarde, D. N. (1997). Dual-axis tomography: an approach with alignment methods that preserve resolution. J. Struct. Biol. 120, 343-352. doi: 10.1006/jsbi.1997.3919

McCartney, A. W., Greenwood, J. S., Fabian, M. R., White, K. A., and Mullen, R. T. (2005). Localization of the tomato bushy stunt virus replication protein p33 reveals a peroxisome-to-endoplasmic reticulum sorting pathway. Plant Cell 17, 3513-3531. doi: 10.1105/tpc.105.036350

McIntosh, R., Nicastro, D., and Mastronarde, D. (2005). New views of cells in 3D: an introduction to electron tomography. Trends Cell Biol. 15, 43-51. doi: 10.1016/j.tcb.2004.11.009

McMahon, H. T., and Gallop, J. L. (2005). Membrane curvature and mechanisms of dynamic cell membrane remodelling. Nature 438, 590-596. doi: 10.1038 /nature04396

Menzel, W., Maiss, E., and Vetten, H. (2009). Nucleotide sequence of a satellite RNA associated with carrot motley dwarf in parsley and carrot. Virus Genes 38, 187-188. doi: 10.1007/s11262-008-0302-5

Miller, D. J., Schwartz, M. D., Dye, B. T., and Ahlquist, P. (2003). Engineered retargeting of viral RNA replication complexes to an alternative intracellular membrane. J. Virol. 77, 12193-12202. doi: 10.1128/Jvi.77.22.12193-122 02.2003

Miller, S., and Krijnse-Locker, J. (2008). Modification of intracellular membrane structures for virus replication. Nat. Rev. Microbiol. 6, 363-374. doi: $10.1038 /$ nrmicro 1890 
Miyanari, Y., Atsuzawa, K., Usuda, N., Watashi, K., Hishiki, T., Zayas, M., et al. (2007). The lipid droplet is an important organelle for hepatitis C virus production. Nat. Cell Biol. 9, 1089-1097. doi: 10.1038/ncb1631

Mochizuki, T., Hirai, K., Kanda, A., Ohnishi, J., Ohki, T., and Tsuda, S. (2009). Induction of necrosis via mitochondrial targeting of melon necrotic spot virus replication protein p29 by its second transmembrane domain. Virology 390, 239-249. doi: 10.1016/j.virol.2009.05.012

Nagy, P. D. (2008). Yeast as a model host to explore plant virus-host interactions. Annu. Rev. Phytopathol. 46, 217-242. doi: 10.1146/annurev.phyto.121407.093958

Nagy, P. D. (2016). Tombusvirus-host interactions: co-opted evolutionarily conserved host factors take center court. Annu. Rev. Virol. 3, 491-515. doi: 10.1146/annurev-virology-110615-042312

Navarro, B., Rubino, L., and Russo, M. (2004). Expression of the cymbidium ringspot virus 33-kilodalton protein in Saccharomyces cerevisiae and molecular dissection of the peroxisomal targeting signal. J. Virol. 78, 4744-4752. doi: 10.1128/JVI.78.9.4744-4752.2004

Nawaz-Ul-Rehman, M. S., Prasanth, K. R., Xu, K., Sasvari, Z., Kovalev, N., De Castro Martin, I. F., et al. (2016). Viral replication protein inhibits cellular cofilin actin depolymerization factor to regulate the actin network and promote viral replicase assembly. PLoS Pathog. 12:e1005440. doi: 10.1371/journal.ppat.1005440

Nishikiori, M., Dohi, K., Mori, M., Meshi, T., Naito, S., and Ishikawa, M. (2006). Membrane-bound tomato mosaic virus replication proteins participate in RNA synthesis and are associated with host proteins in a pattern distinct from those that are not membrane bound. J. Virol. 80, 8459-8468. doi: 10.1128/JVI.00545-06

Novoa, R. R., Calderita, G., Arranz, R., Fontana, J., Granzowf, H., and Risco, C. (2005). Virus factories: associations of cell organelles for viral replication and morphogenesis. Biol. Cell 97, 147-172. doi: 10.1042/BC20040058

Otegui, M. S., and Staehelin, L. A. (2004). Electron tomographic analysis of postmeiotic cytokinesis during pollen development in Arabidopsis thaliana. Planta 218, 501-515. doi: 10.1007/s00425-003-1125-1

Otegui, M. S., Herder, R., Schulze, J., Jung, R., and Staehelin, L. A. (2006). The proteolytic processing of seed storage proteins in Arabidopsis embryo cells starts in the multivesicular bodies. Plant Cell 18, 2567-2581. doi: 10.1105/tpc.106.040931

Otegui, M. S., Mastronarde, D. N., Kang, B. H., Bednarek, S. Y., and Staehelin, L. A. (2001). Three-dimensional analysis of syncytial-type cell plates during endosperm cellularization visualized by high resolution electron tomography. Plant Cell 13, 2033-2051. doi: 10.1105/TPC.010150

Panavas, T., and Nagy, P. D. (2003). Yeast as a model host to study replication and recombination of defective interfering RNA of tomato bushy stunt virus. Virology 314, 315-325. doi: 10.1016/S0042-6822(03)00436-7

Panavas, T., Hawkins, C. M., Panaviene, Z., and Nagy, P. D. (2005). The role of the p33:p33/p92 interaction domain in RNA replication and intracellular localization of p33 and p92 proteins of cucumber necrosis tombusvirus. Virology 338, 81-95. doi: 10.1016/j.virol.2005.04.025

Paul, D., and Bartenschlager, R. (2013). Architecture and biogenesis of plus-strand RNA virus replication factories. World J. Virol. 2, 32-48. doi: 10.5501/wjv.v2.i2.32

Peddie, C. J., and Collinson, L. M. (2014). Exploring the third dimension: volume electron microscopy comes of age. Micron 61, 9-19. doi: 10.1016/j.micron.2014.01.009

Peiró, A., Martínez-Gil, L., Tamborero, S., Pallás, V., Sánchez-Navarro, J. A., and Mingarro, I. (2014). The tobacco mosaic virus movement protein associates with but does not integrate into biological membranes. J. Virol. 88, 3016-3026. doi: 10.1128/JVI.03648-13

Pogany, J., and Nagy, P. D. (2008). Authentic replication and recombination of tomato bushy stunt virus RNA in a cell-free extract from yeast. J. Virol. 82, 5967-5980. doi: 10.1128/Jvi.02737-07

Prod'homme, D., Le, P. S., Drugeon, G., and Jupin, I. (2001). Detection and subcellular localization of the turnip yellow mosaic virus $66 \mathrm{~K}$ replication protein in infected cells. Virology 281, 88-101. doi: 10.1006/viro.2000.0769

Reichel, C., and Beachy, R. N. (1998). Tobacco mosaic virus infection induces severe morphological changes of the endoplasmic reticulum. Proc. Natl. Acad. Sci. U.S.A. 95, 11169-11174.
Restrepo-Hartwig, M. A., and Ahlquist, P. (1996). Brome mosaic virus helicaseand polymerase-like proteins colocalize on the endoplasmic reticulum at sites of viral RNA synthesis. J. Virol. 70, 8908-8916.

Restrepo-Hartwig, M., and Ahlquist, P. (1999). Brome mosaic virus RNA replication proteins $1 \mathrm{a}$ and $2 \mathrm{a}$ colocalize and $1 \mathrm{a}$ independently localizes on the yeast endoplasmic reticulum. J. Virol. 73, 10303-10309.

Richardson, L. G., Clendening, E. A., Sheen, H., Gidda, S. K., White, K. A., and Mullen, R. T. (2014). A unique N-terminal sequence in the carnation italian ringspot virus p36 replicase-associated protein interacts with the host cell ESCRT-I component Vps23. J. Virol. 88, 6329-6344. doi: 10.1128/JVI.03840-13

Rigort, A., and Plitzko, J. M. (2015). Cryo-focused-ion-beam applications in structural biology. Arch. Biochem. Biophys. 581, 122-130. doi: 10.1016/j.abb.2015.02.009

Rigort, A., Bäuerlein, F. J., Villa, E., Eibauer, M., Laugks, T., Baumeister, W., et al. (2012). Focused ion beam micromachining of eukaryotic cells for cryoelectron tomography. Proc. Natl. Acad. Sci. U.S.A. 109, 4449-4454. doi: 10.1073/pnas.1201333109

Risco, C., De Castro, I. F., Sanz-Sanchez, L., Narayan, K., Grandinetti, G., and Subramaniam, S. (2014). Three-dimensional imaging of viral infections. Annu. Rev. Virol. 1, 453-473. doi: 10.1146/annurev-virology-031413-085351

Ritzenthaler, C., Laporte, C., Gaire, F., Dunoyer, P., Schmitt, C., Duval, S., et al. (2002). Grapevine fanleaf virus replication occurs on endoplasmic reticulum-derived membranes. J. Virol. 76, 8808-8819. doi: 10.1128/JVI.76.17.8808-8819.2002

Rochon, D. A., Singh, B., Reade, R., Theilmann, J., Ghoshal, K., Alam, S. B., et al. (2014). The p33 auxiliary replicase protein of cucumber necrosis virus targets peroxisomes and infection induces de novo peroxisome formation from the endoplasmic reticulum. Virology 453, 133-142. doi: 10.1016/j.virol.2013.12.035

Romero-Brey, I., and Bartenschlager, R. (2014). Membranous replication factories induced by plus-strand RNA viruses. Viruses 6, 2826-2857. doi: 10.3390/v6072826

Romero-Brey, I., and Bartenschlager, R. (2015). Viral infection at high magnification: 3D electron microscopy methods to analyze the architecture of infected cells. Viruses 7, 6316-6345. doi: 10.3390/v7122940

Romero-Brey, I., and Bartenschlager, R. (2016). Endoplasmic reticulum: the favorite intracellular niche for viral replication and assembly. Viruses 8:160. doi: 10.3390/v8060160

Rubino, L., and Russo, M. (1998). Membrane targeting sequences in tombusvirus infections. Virology 252, 431-437. doi: 10.1006/viro.1998.9490

Russo, M., Di Franco, A., and Martelli, G. P. (1983). The fine structure of cymbidium ringspot virus infections in host tissues. III. Role of peroxisomes in the genesis of multivesicular bodies. J. Ultrastruct. Res. 82, 52-63. doi: 10.1016/S0022-5320(83)90096-5

Sambade, A., Brandner, K., Hofmann, C., Seemanpillai, M., Mutterer, J., and Heinlein, M. (2008). Transport of TMV movement protein particles associated with the targeting of RNA to plasmodesmata. Traffic 9, 2073-2088. doi: 10.1111/j.1600-0854.2008.00824.x

Schaad, M. C., Jensen, P. E., and Carrington, J. C. (1997). Formation of plant RNA virus replication complexes on membranes: role of an endoplasmic reticulumtargeted viral protein. EMBO J. 16, 4049-4059. doi: 10.1093/emboj/16.13.4049

Schwartz, M., Chen, J. B., Lee, W. M., Janda, M., and Ahlquist, P. (2004). Alternate, virus-induced membrane rearrangements support positive-strand RNA virus genome replication. Proc. Natl. Acad. Sci. U.S.A. 101, 11263-11268. doi: 10.1073/pnas.040157101

Schwartz, M., Chen, J., Janda, M., Sullivan, M., Den Boon, J., and Ahlquist, P. (2002). A positive-strand RNA virus replication complex parallels form and function of retrovirus capsids. Mol. Cell 9, 505-514. doi: 10.1016/S1097-2765(02)00474-4

Seguí-Simarro, J. M., Austin, J. R. II., White, E. A., and Staehelin, L. A. (2004). Electron tomographic analysis of somatic cell plate formation in meristematic cells of Arabidopsis preserved by high-pressure freezing. Plant Cell 16, 836-856. doi: 10.1105/tpc.017749

Sharma, M., Sasvari, Z., and Nagy, P. D. (2010). Inhibition of sterol biosynthesis reduces tombusvirus replication in yeast and plants. J. Virol. 84, 2270-2281. doi: 10.1128/JVI.02003-09

Sharma, M., Sasvari, Z., and Nagy, P. D. (2011). Inhibition of phospholipid biosynthesis decreases the activity of the tombusvirus replicase and alters 
the subcellular localization of replication proteins. Virology 415, 141-152. doi: 10.1016/j.virol.2011.04.008

Shimoni, E., Rav-Hon, O., Ohad, I., Brumfeld, V., and Reich, Z. (2005). Three-dimensional organization of higher-plant chloroplast thylakoid membranes revealed by electron tomography. Plant Cell 17, 2580-2586. doi: 10.1105/tpc.105.035030

Sun, L., Andika, I. B., Shen, J., Yang, D., and Chen, J. (2014). The P2 of wheat yellow mosaic virus rearranges the endoplasmic reticulum and recruits other viral proteins into replication-associated inclusion bodies. Mol. Plant Pathol. 15, 466-478. doi: 10.1111/mpp.12109.

Tabak, H. F., Braakman, I., and Van, D. Z. A. (2013). Peroxisome formation and maintenance are dependent on the endoplasmic reticulum. Annu. Rev. Biochem. 82, 723-744. doi: 10.1146/annurev-biochem-081111-1 25123

Tolley, N., Sparkes, I. A., Hunter, P. R., Craddock, C. P., Nuttall, J., Roberts, L. M., et al. (2008). Overexpression of a plant reticulon remodels the lumen of the cortical endoplasmic reticulum but does not perturb protein transport. Traffic 9, 94-102. doi: 10.1111/j.1600-0854.2007.00670.x

Torrance, L., Cowan, G. H., Gillespie, T., Ziegler, A., and Lacomme, C. (2006). Barley stripe mosaic virus-encoded proteins triple-gene block 2 and gammab localize to chloroplasts in virus-infected monocot and dicot plants, revealing hitherto-unknown roles in virus replication. J. Gen. Virol. 87, 2403-2411. doi: 10.1099/vir.0.81975-0

Tsujimoto, Y., Numaga, T., Ohshima, K., Yano, M. A., Ohsawa, R., Goto, D. B., et al. (2003). Arabidopsis TOBAMOVIRUS MULTIPLICATION (TOM) 2 locus encodes a transmembrane protein that interacts with TOM1. EMBO J. 22, 335-343. doi: 10.1093/emboj/cdg034

Turner, K. A., Sit, T. L., Callaway, A. S., Allen, N. S., and Lommel, S. A. (2004). Red clover necrotic mosaic virus replication proteins accumulate at the endoplasmic reticulum. Virology 320, 276-290. doi: 10.1016/j.virol.2003. 12.006

Verchot, J. (2011). Wrapping membranes around plant virus infection. Curr. Opin. Virol. 1, 388-395. doi: 10.1016/j.coviro.2011.09.009

Voeltz, G. K., Prinz, W. A., Shibata, Y., Rist, J. M., and Rapoport, T. A. (2006). A class of membrane proteins shaping the tubular endoplasmic reticulum. Cell 124, 573-586. doi: 10.1016/j.cell.2005.11.047

Wakefield, S., and Tear, G. (2006). The Drosophila reticulon, Rtnl-1, has multiple differentially expressed isoforms that are associated with a subcompartment of the endoplasmic reticulum. Cell. Mol. Life Sci. 63, 2027-2038. doi: 10.1007/s00018-006-6142-3

Wan, J., Basu, K., Mui, J., Vali, H., Zheng, H., and Lalibert,é, J.-F. (2015). Ultrastructural characterization of turnip mosaic virus-induced cellular rearrangements reveals membrane-bound viral particles accumulating in vacuoles. J. Virol. 89, 12441-12456. doi: 10.1128/JVI.02 138-15

Wang, A. (2015). Dissecting the molecular network of virus-plant interactions: the complex roles of host factors. Annu. Rev. Phytopathol. 53, 45-66. doi: 10.1146/annurev-phyto-080614-120001

Wei, T., and Wang, A. (2008). Biogenesis of cytoplasmic membranous vesicles for plant potyvirus replication occurs at endoplasmic reticulum exit sites in a COPI- and COPII-dependent manner. J. Virol. 82, 12252-12264. doi: 10.1128/JVI.01329-08

Wei, T., Zhang, C., Hou, X., Sanfaçon, H., and Wang, A. (2013). The SNARE protein Syp71 is essential for turnip mosaic virus infection by mediating fusion of virus-induced vesicles with chloroplasts. PLoS Pathog. 9:e1003378. doi: 10.1371/journal.ppat.1003378

Welsch, S., Miller, S., Romero-Brey, I., Merz, A., Bleck, C. K., Walther, P., et al. (2009). Composition and three-dimensional architecture of the dengue virus replication and assembly sites. Cell Host Microbe 5, 365-375. doi: 10.1016/j.chom.2009.03.007
Wollert, T., and Hurley, J. H. (2010). Molecular mechanism of multivesicular body biogenesis by ESCRT complexes. Nature 464, 864-869. doi: $10.1038 /$ nature08849

Wollert, T., Wunder, C., Lippincott-Schwartz, J., and Hurley, J. H. (2009). Membrane scission by the ESCRT-III complex. Nature 458, 172-177. doi: 10.1038/nature07836

$\mathrm{Xu}, \mathrm{K}$., and Nagy, P. D. (2014). Expanding use of multi-origin subcellular membranes by positive-strand RNA viruses during replication. Curr. Opin. Virol. 9, 119-126. doi: 10.1016/j.coviro.2014.09.015

$\mathrm{Xu}, \mathrm{K}$., and Nagy, P. D. (2015). RNA virus replication depends on enrichment of phosphatidylethanolamine at replication sites in subcellular membranes. Proc. Natl. Acad. Sci. U.S.A. 112, E1782-E1791. doi: 10.1073/pnas.1418971112

$\mathrm{Xu}$, K., and Nagy, P. D. (2016). Enrichment of phosphatidylethanolamine in viral replication compartments via co-opting the endosomal Rab5 small GTPase by a positive-strand RNA virus. PLoS Biol. 14:e2000128. doi: 10.1371/journal.pbio.2000128

$\mathrm{Xu}, \mathrm{K}$., and Nagy, P. D. (2017). Sterol binding by the tombusviral replication proteins is essential for replication in yeast and plants. J. Virol. 91:e01984-16. doi: 10.1128/jvi.01984-16

Yamanaka, T., Imai, T., Satoh, R., Kawashima, A., Takahashi, M., Tomita, K., et al. (2002). Complete inhibition of tobamovirus multiplication by simultaneous mutations in two homologous host genes. J. Virol. 76, 2491-2497. doi: 10.1128/JVI.76.5.2491-2497.2002

Yamanaka, T., Ohta, T., Takahashi, M., Meshi, T., Schmidt, R., Dean, C., et al. (2000). TOM1, an Arabidopsis gene required for efficient multiplication of a tobamovirus, encodes a putative transmembrane protein. Proc. Natl. Acad. Sci. U.S.A. 97, 10107-10112. doi: 10.1073/pnas.170295097

Yuan, X., Cao, Y., Xi, D., Guo, L., Han, C., Li, D., et al. (2006). Analysis of the subgenomic RNAs and the small open reading frames of beet black scorch virus. J. Gen. Virol. 87, 3077-3086. doi: 10.1099/vir.0.81928-0

Zárský V., and Cvrčková F. (2014). Plant Cell Morphogenesis: Methods and Protocols. Methods in Molecular Biology, Vol. 1080. ed J. M. Walker (New York, NY: Humana Press).

Zhang, G., and Sanfaçon, H. (2006). Characterization of membrane association domains within the tomato ringspot nepovirus X2 protein, an endoplasmic reticulum-targeted polytopic membrane protein. J. Virol. 80, 10847-10857. doi: 10.1128/JVI.00789-06

Zhang, J., Diaz, A., Mao, L., Ahlquist, P., and Wang, X. (2012). Host acyl coenzyme A binding protein regulates replication complex assembly and activity of a positive-strand RNA virus. J. Virol. 86, 5110-5121. doi: 10.1128/JVI.06701-11

Zhang, J., Zhang, Z., Chukkapalli, V., Nchoutmboube, J. A., Li, J., Randall, G., et al. (2016). Positive-strand RNA viruses stimulate host phosphatidylcholine synthesis at viral replication sites. Proc. Natl. Acad. Sci. U.S.A. 113, E1064E1073. doi: 10.1073/pnas.1519730113

Zhang, K., Zhang, Y., Yang, M., Liu, S., Li, Z., Wang, X., et al. (2017). The barley stripe mosaic virus $\gamma \mathrm{b}$ protein promotes chloroplast-targeted replication by enhancing unwinding of RNA duplexes. PLoS Pathog. 13:e1006319. doi: 10.1371/journal.ppat.1006319

Conflict of Interest Statement: The authors declare that the research was conducted in the absence of any commercial or financial relationships that could be construed as a potential conflict of interest.

Copyright (c) 2018 Jin, Cao, Wang, Jiang, Wan, Laliberté and Zhang. This is an open-access article distributed under the terms of the Creative Commons Attribution License (CC BY). The use, distribution or reproduction in other forums is permitted, provided the original author(s) and the copyright owner are credited and that the original publication in this journal is cited, in accordance with accepted academic practice. No use, distribution or reproduction is permitted which does not comply with these terms. 